\title{
Test and Analysis of Full-Scale 27.5-Foot-Diameter Stiffened Metallic Launch Vehicle Cylinders
}

\author{
Andrew E. Lovejoy ${ }^{1}$, Mark W. Hilburger ${ }^{2}$ \\ NASA Langley Research Center, Hampton, VA 23681, United States of America \\ and \\ Nathaniel W. Gardner ${ }^{3}$ \\ Analytical Services and Materials, Inc., Hampton, VA 23666, United States of America
}

\begin{abstract}
The Shell Buckling Knockdown Factor Project (SBKF) was established with the goal of developing improved (i.e., less-conservative, more robust) shell buckling knockdown factors (KDFs) for modern launch-vehicle structures. To this end, SBKF has engaged in several activities to support the development, validation, and implementation of the new design factors, including subscale and full-scale structural testing. Tests on eight different subscale, 8-foot-diameter, integrally stiffened aluminum-lithium 2195 (Al-Li 2195) cylinders were conducted in order to obtain the majority of the required validation data. In addition, two full-scale, 27.5-foot-diameter, Al-Li 2195, integrally stiffened cylinders were tested to provide additional validation data and to determine structural scaling trends. Presented herein are the details of a recent analysis model development and test and analysis correlation effort on the full-scale test articles. The effects of selected modeling assumptions and approaches are discussed, and results from a modeling sensitivity study are presented. It was found that simplified finite element models, that assume nominal test article geometry and material properties, can predict the overall response characteristics well. However, several discrepancies in the test and analysis results were observed. A sensitivity study was performed to determine the effects of several modeling assumptions and address the observed discrepancies. The results from the study indicated that the evolution of local skin pocket buckling and the presence of residual stresses due to the manufacturing process can have a significant influence on the predicted buckling response of the cylinders considered.
\end{abstract}

\section{Nomenclature}

$\begin{array}{ll}\text { Al-Li } 2195 & =\text { aluminum-lithium } 2195 \\ \text { DIC } & =\text { digital image correlation } \\ \text { ET } & =\text { Space Shuttle External Tank } \\ \text { ETTA } & =\text { finite element model } \\ \text { FEM } & =\text { inner mold line/outer mold line } \\ \text { IML/OML } & =\text { knockdown factor } \\ \text { KDF } & =\text { liquid hydrogen } \\ \text { LH2 } & =\text { liquid oxygen } \\ \text { LO2 } & =\text { Load Test Annex located in building } 4619 \text { at MSFC } \\ \text { LTA } & =\text { linear voltage displacement transducer } \\ \text { LVDT } & \text { NASA Marshall Space Flight Center }\end{array}$

\footnotetext{
${ }^{1}$ Research Aerospace Engineer, Structural Mechanics and Concepts Branch, NASA Langley Research Center, Mail Stop 190, Hampton, Virginia 23681, Associate Fellow AIAA.

${ }^{2}$ Senior Research Engineer, Structural Mechanics and Concepts Branch, NASA Langley Research Center, Mail Stop 190, Hampton, Virginia 23681, Senior Member AIAA.

${ }^{3}$ Digital Image Correlation Specialist, Analytical Services and Materials, Inc., Hampton, Virginia 23666. 


\begin{tabular}{|c|c|c|}
\hline NESC & $=$ & NASA Engineering and Safety Center \\
\hline RS1 & $=$ & residual stress model, forming stresses only included \\
\hline $\mathrm{RS} 2$ & $=$ & residual stress model, forming and welding stresses included \\
\hline SBKF & $=$ & Shell Buckling Knockdown Factor Project \\
\hline SPB & $=$ & simulated pocket buckling model, using nonlinear material properties \\
\hline TA & $=$ & test article \\
\hline$b_{r}$ & $=$ & circumferential stiffener spacing \\
\hline$b_{s}$ & $=$ & axial stiffener spacing \\
\hline$H$ & $=$ & stiffener height, measured from outer mold line \\
\hline$L F$ & $=$ & load factor, $L F=P / P_{c l}$ \\
\hline$M$ & $=$ & applied bending moment \\
\hline$M_{c r}$ & $=$ & critical buckling load under pure bending moment \\
\hline$P$ & $=$ & applied total axial load \\
\hline$P_{b i f}$ & $=$ & finite element linear buckling load of detailed perfect model \\
\hline$P_{c l}$ & $=$ & classical buckling load under pure axial loading \\
\hline$P_{c r}$ & $=$ & critical buckling load of as-manufactured imperfect cylinder under pure axial loading \\
\hline$R$ & $=$ & cylinder radius (typically taken as OML) \\
\hline$t$ & $=$ & skin thickness \\
\hline$t_{r}$ & $=$ & circumferential stiffener thickness \\
\hline$t_{s}$ & $=$ & axial stiffener thickness \\
\hline$t_{t}$ & $=$ & transition region skin thickness \\
\hline$t_{w}$ & $=$ & weld land thickness \\
\hline$u, v, w$ & $=$ & axial, circumferential, and radial displacements \\
\hline$w_{w}$ & $=$ & weld land half width \\
\hline$x, \theta, z$ & & axial, circumferential, and radial coordinates \\
\hline$\gamma$ & $=$ & knockdown factor, $\gamma=P_{c r} / P_{c l}$ \\
\hline
\end{tabular}

\section{Introduction}

$\mathrm{H}$ igh-performance launch vehicle shell structures are inherently thin walled because of weight and performance considerations, and are often subjected to destabilizing loads during flight. Thus, buckling is an important and often critical consideration in the design of these structures, and reliable, validated design criteria for thin-walled shells are needed. Unfortunately, the current buckling design guidelines (Refs. 1-4) have not been updated since they were first published by NASA in the late 1960s and early 1970s, and they do not take full advantage of modern materials, precision manufacturing processes, and new structural concepts being considered in for the next generation of launch vehicles.

In order to update these design recommendations, the NASA Engineering and Safety Center (NESC) established the Shell Buckling Knockdown Factor Project (SBKF) in the spring of 2007 with the goal of developing improved (i.e., less-conservative, more robust), shell buckling design factors (a.k.a. knockdown factors, KDF) for modern launch-vehicle structures. To this end, SBKF has engaged in several activities to support the development, validation, and implementation of the new design factors, including subscale and full-scale structural testing. The primary objectives of the test program were to:

1. Provide validation data for high-fidelity structural analysis models and new design KDFs.

2. Verify the performance and behavioral characteristics of a variety of buckling-critical launch-vehicle-like structural designs subjected to relevant loading conditions.

3. Determine the effects of common structural details such as weld lands on the buckling response.

4. Understand the effects of scale-up from subscale to full-scale on the buckling response.

SBKF has recently completed a comprehensive test program to investigate the buckling response of integrallystiffened metallic cylinders that included the testing of eight subscale 8-ft-diameter cylinders and two full-scale 27.5$\mathrm{ft}$-diameter cylinders. The test article (TA) designs were developed to be representative of past and proposed launch vehicle cylinder designs, and they span a significant portion of the design space. Tests on eight different subscale, 8foot-diameter, integrally stiffened aluminum-lithium 2195 (Al-Li 2195) cylinders were conducted in order to obtain the majority of the required validation data. ${ }^{5}$ In addition, two full-scale, 27.5-foot-diameter, Al-Li 2195, integrally stiffened cylinders were tested to provide additional validation data and to determine structural scaling trends. ${ }^{6}$ The subscale and full-scale TAs consisted of multiple curved panel sections that were friction stir welded together to form 
the complete cylinder. Different stiffener patterns were considered and included orthogrid and isogrid patterns. ${ }^{5-7}$ The TAs were mounted into purpose-built test facilities and subjected to combinations of uniaxial compression, bending and internal pressure loads to simulate typical launch vehicle loading conditions that can cause buckling. ${ }^{5,6}$ The data gathered from this test program is currently being used to develop and validate new analysis-based KDFs and design guidelines for these stiffened metallic cylinders. In this paper, details of the analysis model development and test to analysis correlation of the full-scale TAs are presented. The effects of selected modeling assumptions and approaches are discussed, results from a sensitivity study are presented and discussed, and closing conclusions are presented.

\section{Test Article Description}

Two full-scale 27.5-ft orthogrid stiffened cylinder TAs were designed and fabricated from existing Space Shuttle External Tank (ET) panels. While fabricated from ET panels, the TAs do not represent any actual ET structural configuration, and they were designed to satisfy specific SBKF testing goals. The TAs were approximately 242 inches in length and were fabricated from Al-Li 2195, and comprise eight panels that were friction stir welded along the axial direction to form complete cylinders. All panels used in the construction of the TAs were formed to an outer mold line (OML) radius of 168.0 inches prior to heat treatment. These heat-treated panels were pulled together during the welding process to form a completed a barrel with a final OML of 165.5 inches. Panels used to construct the TAs consisted of stiffened acreage regions, unstiffened weld land regions, and transition regions between the acreage and weld lands. Figure 1 defines the acreage orthogrid design parameters, where $t$ is the skin thickness, $t_{s}$ is the axial stiffener thickness, $b_{s}$ is the axial stiffener spacing, $t_{r}$ is the circumferential stiffener thickness, $b_{r}$ is the circumferential stiffener spacing, and $H$ is the height of the stiffener measured from the OML of the cylinder. The nominal orthogrid stiffened acreage design variable values used in the construction of the two ET-derived TAs (ETTAs), designated as ETTA1 and ETTA2 and described in the next paragraph, are listed in Table 2. While the nominal dimensions apply to the majority of the orthogrid structure in the TAs, highly tailored regions were present in the heavily stiffened portions of ETTA2 as a consequence of ET-specific functionality. The acreage orthogrid was transitioned into the axial weld lands, and at the top and bottom of the cylinders (the circumferential weld land of the panels). The stiffeners were tapered down in the transition regions, and included tapered-height stiffeners with increased skin thickness, as shown in Fig. 2. Typically, the thickness of the transition region, $t_{t}$, was mid-way between the thicknesses of the acreage skin and the weld land. The thickness of the weld lands, $t_{w}$, had a nominal value of 0.325 inches. The halfwidth of the axial weld land, $\mathrm{w}_{\mathrm{w}}$, which represents the distance from the stringer runout to the center of the weld land, was nominally 1.68 inches. The weld land thickness at the top and bottom of the cylinders extended about 3.0 inches beyond the end of the stringers

The first ETTA was designated ETTA1, and was designed for buckling under uniform compression loading. ETTA1 incorporated two essentially identical lightly stiffened panel designs, which resulted in a barrel with a nominally uniform design ideal for uniform compression loading, Fig. 3a. The second TA was designated ETTA2, and was designed for buckling under combined compression/bending loading. ETTA2 contained a combination of lightly stiffened panels, similar to ETTA1, and heavily stiffened panels with various degrees of heavily stiffened regions, Fig. 3b. The coordinate systems for the TAs were oriented such that the x-axis was through the center of arc of Panel A and Panel E for ETTA1 and ETTA2, respectively, as shown in Fig 4. With the z-axis oriented up, the yaxis was through the center of arc of Panel $\mathrm{C}$ and Panel $\mathrm{G}$ for ETTA1 and ETTA2, respectively. In this paper, the reported angles for circumferential location are measured positive from the x-axis, 0 -degrees, in the direction of the y-axis.

\section{Test Description}

\section{A. Facility}

The full detailed test description is presented in Ref. 6, and is summarized herein. The test facility used to test the full-scale 27.5-foot-diameter cylinders was designed and assembled at Marshall Space Flight Center (MSFC), and was located in the building 4619 Load Test Annex (LTA). The test setup comprises the LTA crosshead, hydraulic load lines, an upper load introduction cylinder (liquid oxygen (LO2) tank ring and simulator), the TA, the lower load introduction cylinder (liquid hydrogen (LH2) tank ring and simulator), and the LTA floor, as shown in Fig. 5. The components between the LTA floor and crosshead, termed the stack, include the LH2 load ring through the load lines, and is nearly $70-\mathrm{ft}$ tall. The upper and lower load introduction cylinders are heritage hardware that was developed for testing the ET Intertank, and were designed to represent stiffness of the LO2 tank (upper, or top) and LH2 tank (lower, or bottom). The test system also includes the load control system, the pressurization system, and data acquisition systems. The test system was designed to apply various combinations of axial compression, bending, and internal 
pressure. An integrated instrumentation structure was constructed inside the test stack to mount linear voltage displacement transducers (LVDTs), cameras and lights. Instrumentation used during the test included photographic/video systems, strain gages, LVDTs, pressure transducers, load cells, high-fidelity digital image correlation (DIC) techniques and high-speed digital video. External instrumentation was attached directly to LTA structure or independent mounting towers.

\section{B. Instrumentation}

For ETTA1, there were 842 strain gages that included numerous sets of back-to-back strain gages positioned at each of the eight weld lands and on the acreage skin pockets and stiffeners to assess the overall global behavior of the TA. Panels A and E were more highly instrumented to obtain additional detailed strain measurements for model validation purposes. In addition to the TA strain gages, back-to-back axial strain gages were positioned around the circumference of the upper and lower simulators near the TA-to-simulator interfaces to monitor the load introduction into the TA. For ETTA2, there were 1168 strain gages. Similar to ETTA1, ETTA2 had numerous sets of back-to-back strain gages positioned on each of the eight weld lands and on the acreage skin pockets and stiffeners to assess the overall global behavior of the TA. In this case, all of the ETTA2 panels had similar strain gage patterns that were used to assess the overall response of the structure. The back-to-back axial gages on the upper and lower simulators used during ETTA1 testing were retained and unchanged for the ETTA2 testing. Axial locations used to examine the strain in the TA in the results sections are identified in Fig. 6, where the blue dashed lines identify the locations at the midlength and near the top and bottom of the TA.

Displacement measurements were made at discrete locations using numerous LVDTs. In particular, radial displacements were measured on the TAs at six inner mold line (IML) locations on each of the eight panels. The six LVDTs were located at the weld land and mid-arc of the panel in positions near the top, near the bottom, and at the mid-length, and were numbered as shown in Fig. 6. Additional LVDTs were positioned on the top and bottom attachment rings to characterize the axial, radial and tangential displacements at the ends of the TAs. The axial displacements were measured using LVDTs on ETTA1 were located at the 45, 135, 225 and 315 degree locations on the top and the bottom attachment rings. These LVDTs were mounted on instrumentation structure inside the TA, and took measurements from cantilevered metal beams (diving boards) that were attached to the TA attachment rings as shown in Fig. 7(a). During early subcritical load cases, load cases not intended to induce buckling of the cylinder (described in Section IV.A), simulator strain gage data indicated that the rings rotated under load (manifested as large bending strains adjacent to the TA/simulator interfaces). Rotation of the rings meant that the displacements measured by the axial LVDTs were a combination of axial displacement and rotation of the diving board. For simplicity, and to keep to the testing schedule, a modified arrangement was developed whereby additional LVDTs were added to the outside of the test setup. These additional LVDTs were mounted on the simulator stiffeners, as depicted in the schematic shown in Fig. 7(b). While not ideal, it was anticipated that the errors would be small compared to the endshortening values. ETTA2 used a similar arrangement of LVDTs as ETTA1, with the exception that the axial LVDTs used for end-shortening measurements were mounted to the instrumentation structure inside the TA with a dual LVDT arrangement on each diving board, as shown in Fig. 8, to measure ring rotation from a common reference point.

Global displacements and strains were measured using six DIC systems, that were used to monitor the OML of ETTA1 and ETTA2. However, the field of view on ETTA2 was extended to include the attachment rings and approximately 12 inches of the simulators adjacent to the rings. The external DIC systems utilized "L" markers at known locations, such as the marker shown in Fig. 9, to identify specific locations for DIC data processing. These "L" markers can also be used for other purposes, such as to measure local displacements or enable average local strain measurements between pairs of "L" markers. Six high-speed cameras were set up to capture the expected transient buckling events during the final load sequence, as well as any unexpected events during subcritical load sequences.

\section{Installation}

In an effort to produce uniform load introduction into the TA, the attachment ring-to-simulator interface was shimmed during installation of the TA into the stack (recall Fig. 5) to remove gaps between interface surfaces. Shimming was performed while monitoring strain gages and DIC data to observe the response of the TA during the shimming process. The shimming process required several steps, starting with the TA being placed in position atop the LH2 simulator. The bolts were installed in the lower attachment ring to connect the ring to the LH2 simulator without being fully tightened. The LTA crosshead was lowered so that the LO2 assembly weight was supported by the TA, and the gaps at the upper and lower interfaces were measured around the circumference. The LTA crosshead was raised and shims installed as specified by the measured gaps. The LTA crosshead was again lowered to place the LO2 assembly weight on the TA, and the gaps evaluated and strains measured. This process was repeated until all gaps were removed to the greatest extent possible, and the strains were as uniform around the circumference as 
possible. The shimming process for ETTA2 was modified from that for ETTA1 due to the nonuniform construction of ETTA2. Therefore, ETTA2 was shimmed to match a strain distribution predicted by finite element analysis of the stack. Another reason for using predicted strains for ETTA2 shimming was the nonuniform strain distribution observed during the ETTA1 testing, which will be discussed subsequently in Section IV.B. For both TAs, once shimming was complete, the upper and lower simulator/ring interface bolts were tightened and the final strain distribution recorded.

\section{Loading}

Load cases applied during testing were defined using the classical buckling load under pure compression, $P_{c l}$, that was determined using an eigenvalue analysis for the perfect cylinder with nominal geometry (see Section IV). During design, $P_{c l}$ is typically calculated by a classical analytical approach or by using a finite element model (FEM) having smeared stiffeners. The load cases were defined in terms of percentages of $P_{c l}$, the classical buckling load under pure moment, $M_{c l}$, and internal pressure. The value for $M_{c l}$ was determined from $P_{c l}$ by setting the maximum running load from pure compression critical buckling equal to the maximum compression running load associated with the critical bending moment. Mathematically, this association is expressed as $M_{c l}=\left(R^{*} P_{c l}\right) / 2$, where $R$ is the cylinder radius taken to be the OML radius. While using this expression was an approximate method of determining $M_{c l}$, using this expression was deemed acceptable for determining load case definitions. Subcritical cases included pure axial compression, pure internal pressure, combined axial compression and bending moment, and combined axial load and bending moment and pressure. These subcritical load cases were applied to examine the response of the TAs under various loading conditions, but without buckling or material failure (or yielding) occurring. The maximum total load for each load case was defined as $\mathrm{A}^{*} P_{c l}+\mathrm{B}^{*} M_{c l}+\mathrm{C}$ psi, where A and $\mathrm{B}$ are load factors for axial compression and bending moment, respectively, and $\mathrm{C}$ is the applied pressure. For example, a load case with $20 \% P_{c l}, 20 \% M_{c l}$, and 1.0 psi of internal pressure would be represented as $0.2 P_{c l}+0.2 M_{c l}+1.0$ psi. For ETTA1, there were 16 subcritical load cases plus one critical load case loaded under uniform axial compression and $1.0 \mathrm{psi}$ internal pressure until buckling occurred (designated LS17). For ETTA2, there were 17 subcritical load cases plus one critical load case loaded with $0.5 \mathrm{psi}$ internal pressure and combined axial compression and bending, with $\mathrm{A}=\mathrm{B}$, until buckling occurred (designated LS18).

\section{Baseline Models}

\section{A. Modeling Approach}

The test stack was modeled and analyzed using the Abaqus finite element software. ${ }^{8}$ The stack FEM shown in Fig. 10 consisted of shell and beam elements. The general-purpose Abaqus S3R triangular and S4R quadrilateral shell elements were used to model the TAs. These shell elements allow for finite membrane strains and large rotations, and also permit transverse shear flexibility. The element nodes include 3 translational degrees of freedom and 3 rotational degrees of freedom. The attachment ring region was modeled using a laminated shell approach whereby the attachment ring webs, potting material, and the TA (circumferential weld land region) were modeled as separate layers in a single laminate property definition. Shell elements were also used to model the simulators and load rings. The load lines and load attachment structure (e.g., clevises) were modeled using Abaqus B31 beam elements.

Baseline FEMs were generated using nominal geometry and material properties, however, design details such as filets and stiffener intersection "nodes" (intersection of axial and circumferential stiffeners, including the fillets) were neglected. The FEM included clamped boundary conditions at the base of the LH2 load ring and pinned boundary conditions at the ends of the load lines attached to the LTA crosshead. The reference surfaces of the baseline FEMs were taken to be the IML of the acreage skin and the mid-plane of the stiffeners. This reference surface definition ensured that the acreage stiffener height was accurate. Al-Li 2195 material properties were used, and were assumed to be linear elastic and isotropic with a Young's modulus of $11.0 \mathrm{Msi}$, a Poisson's ratio of 0.33 , and a density of 0.098 $\mathrm{lbm} / \mathrm{in}^{3}$.

Baseline predictions of the TA response included linear buckling, nonlinear static and nonlinear transient analyses. Linear buckling analysis provided the value for the geometrically perfect detailed finite element model, $P_{b i f}$, which is different from the classical buckling load, $P_{c l}$, that was used to define load cases. That is, $P_{b i f}$ includes details of the structure such as weld lands and discrete stiffeners, whereas $P_{c l}$ is determined from the closed-form solution using smeared stiffeners. Nonlinear static analysis was used to determine the subcritical load case response, and to determine the initial response during the final load case. Nonlinear transient analysis was used to determine the response prior to buckling and through buckling into the post-buckling region. In order to determine the KDF, defined as $\gamma=P_{c r} / P_{c l}$, the critical buckling load of the as-manufactured imperfect cylinder, $P_{c r}$, was needed. The value for $P_{c r}$ was determined 
by conducting nonlinear static analysis under applied displacement up to a percentage of the expected maximum load that was below the load at which pocket buckling was expected to occur, and then changing to nonlinear transient analysis for the remainder of the analysis up to buckling and into the post-buckling response region. All test prediction analyses were performed with as-manufactured imperfect cylinder model that had the geometrically perfect nodes perturbed based upon a measured structured-light-scanned imperfection of the as-manufactured TA. Measured geometric imperfections were obtained using a structured-light approach, and are shown in Fig. 11. The imperfections were incorporated into the models by perturbing the radial location of all TA nodes according to the imperfection data. Note that there are severe inward imperfections at the weld lands, and that these areas exhibit the largest magnitudes of the imperfections. Results for the baseline models are presented in the following section.

\section{B. Results}

Typical predicted responses used for test and analysis correlation were plotted with respect to the normalized load, $P / P_{c l}$, where $P$ is the applied axial compression load. Plots included normalized load versus end-shortening or axial strain to characterize global stiffness, axial and hoop strain distribution around the circumference of the TA at specified load levels to evaluate load introduction, contour plots of OML displacements (axial and radial), load versus strain response curves at strain gage locations, and load versus displacement curves. Test and analysis correlation is presented herein for ETTA1 under LS17 load conditions, which was intended to be a load sequence to buckling failure. However, during the test, the applied load reached a value well above the pretest predictions. Because of safety considerations associated with failure of the pressurized TA at higher than expected loads, axial loading was halted, axial load was reduced to a lower value, the pressure was reduced to $0.6 \mathrm{psi}$, and then axial load increased until buckling occurred. In this paper, test and analysis correlation for ETTA1 is presented only for the initial part of the LS17 testing that included $1.0 \mathrm{psi}$ internal pressure. Test and analysis correlation for ETTA2 is presented herein for the LS18 load case in which buckling failure did occur during the test.

Comparison of the test and analysis normalized load versus. end shortening response of ETTA1 is shown in Fig. 12 for the load sequence LS17. Three curves for the test data are presented. The first curve is the end shortening based on the original LVDT configuration (recall Fig. 6a), and is labeled as "Test: LVDT Only" in Fig. 12. The second curve has a correction applied to the end shortening by accounting for rotation using both the inside and outside LVDTs (see Fig 6b) where the IML axial reading is adjusted based on the calculated rotation of the ring, and is labeled as "Test: Modified 1" in Fig. 12. The third curve accounts for ring rotations, but also includes an adjustment based on the strain of the simulators between the mounting point of the outer LVDT on the stringer and the point on the diving board to which the LVDT is connected, and is labeled as "Test: Modified 2" in Fig. 12. Note that the original configuration test curve is less stiff than the analysis result, but applying the corrections makes the two modified curves stiffer than the analysis. Also note that including the strain in the Modified 2 calculation results in slightly less correction to the original LVDT Only method than Modified 1 that corrects only using rotation of the ring, but this result is expected as stated previously in Section III.B. Initial slopes of the test curves do not agree with the analysis results, which is between the LVDT Only and modified curves, but the second modification that accounts for strains in the simulator agrees well with test above a normalized load of about 0.58 .

It was decided that the test results for end shortening based on the LVDTs were of unknown accuracy, especially considering the mounting method of the outside LVDTs. Therefore, comparison was made of normalized load versus average axial strain in the weld lands and the center of the panels. Average strains were calculated using axial displacements measured by the aforementioned DIC "L" markers (recall Fig. 8) that are located in-line with the radial LVDTs shown in Fig. 5, and using the markers closest to the TA-to-simulator interface to address the greatest length possible of the TA. The average strains for ETTA1 LS17 are shown in Fig. 13, where it is observed that the test has nonlinear behavior corresponding to a reduced effective axial stiffness that begins at a much lower load level than the analysis. Reduction of axial stiffness occurs at a normalized load value of $P / P_{c l}=0.40$ (or $P=40 \% P_{c l}$ ), compared to the analysis which predicts this behavior at a normalized load value of 0.55 .

Typical response of ETTA1 radial LVDTs is shown in Figs. 14 and 15 for panel $\mathrm{H}$ weld land and center of panel, respectively. Note that the response in the panel center exhibits better agreement than in the weld land, and that trend is consistent throughout the TA. In particular, discrepancies are significant in the weld land mid-length radial displacement during pressurization, which leads to an overall offset in the predicted radial response compared to the test. Significant discrepancies in the radial response are also observed at higher normalized load levels, above about 0.7 , at the mid-length of the TA.

Axial membrane strain data was used to assess the load introduction into the TA. The ETTA1 axial membrane strain circumferential traces are shown in Figs. 16 and 17, at loads of $1.0 \mathrm{psi}$ and $15 \% P_{c l}$ and $1.0 \mathrm{psi}$ and $59 \% P_{c l}$, respectively. Strain comparisons between test and analysis exhibited good correlation overall, usually within a few percent but less than $10 \%$, indicating good modeling of the load introduction, especially at lower loads. However, 
local areas of the curves demonstrated poorer test and analysis correlation at the higher load level, with some differences as high as $30-35 \%$, indicating a need for further investigation and analyses.

Displacement contour plots were used to examine the overall deformations of the TAs. Axial deformation contours for ETTA1 are shown in Fig. 18, where the TA is subjected to an axial compression load of $59 \% P_{c l}$ and an internal pressure of 1.0 psi. Radial deformation contours are shown in Figs. 19 and 20, where the TA is subjected to an internal pressure of $1.0 \mathrm{psi}$ and an axial compression load of $15 \% P_{c l}$ and $59 \% P_{c l}$, respectively. The test and analysis exhibit similar overall displacements, including the presence of local pocket buckling at the higher load levels, however, the patterning of the pocket buckling shows discrepancies between test and analysis. Radial displacement delta contour plots are shown in Fig. 21 for the radial displacement contour values at $45 \% P_{c l}$ and 1.0 psi internal pressure minus the radial displacement contour values at $1.0 \mathrm{psi}$. By subtracting out the radial displacements at $1.0 \mathrm{psi}$, which are larger in magnitude than the pocket buckling displacements, the pocket buckling is identified by the inward and outward displacements between stiffeners. Results in Fig. 21 indicate that pocket buckling is well developed adjacent to the weld lands in the DIC test data at this load level, while the analysis data shows only a few pocket buckling locations adjacent to the weld lands at this load level. When pocket buckling does develop at higher load levels in the analysis, that pocket buckling is concentrated at the panel centers and doesn't exhibit the same amount of buckling adjacent to the weld lands that is observed in the test data (recall Fig. 20). This difference in the development and patterning of the observed pocket buckling development adjacent to the weld lands is the most likely contributor to the discrepancy between the predicted and measured nonlinear response discussed previously, recall Fig. 13, as well as discrepancies in measured radial displacements and local strains, recall Figs. 14. Also, it is important to note the scalloped axial deformations close to the boundaries in Fig. 18, where the axial deformations are more pronounced at the weld lands than in the center of the panels.

The nonuniform displacement leads to nonuniform axial strain behavior at the boundaries (recall Fig. 16) that was not consistent with the uniform strain distribution that was assumed during the shimming of ETTA1 when the TA was installed in the test stack. This observed nonuniform axial strain distribution in ETTA1 was a contributing factor for determining that ETTA2 should be shimmed during installation to match a distribution near the boundaries that was predicted by analysis. The strain distribution predicted under the weight of the LO2 simulator and LO2 ring is shown in Fig. 22 and was used to perform strain matching of ETTA2 during shimming. The figure shows the scalloped strain distribution, as well as reduced strain in the areas of the heavily-stiffened panels. While this strain variation was small, about $\pm 6 \mu \varepsilon$, compared to the strains at weld land and global buckling, strain matching during shimming was done as an additional attempt to improve accuracy since shimming was going to be done.

The same types of data examined for ETTA1 were examined for ETTA2, where test and analysis correlation is presented for LS18. The normalized load versus end shortening of ETTA2 is shown in Fig. 23, based on calculations using the pairs of axial LVDTs, where good test and analysis agreement is observed, within $5 \%$ until just prior to first buckling predicted by the analysis. The main difference between the test and analysis is the lower buckling load of the weld lands predicted by the analysis compared to the test. The test and analysis KDF values are calculated to be 0.82 and 0.74 , respectively, and both are significantly higher than $\gamma=0.54$ based on the current design recommendations for a uniform orthogrid cylinder having all the heavily-stiffened design shown in Table 2. ${ }^{1}$ Another difference is the stiffness of the TA at higher load levels prior the first buckling event, where the analysis predicts a slightly more nonlinear response than the test.

Radial displacements at the E/F weld land and center of panel E are shown in Figs. 24 and 25, respectively, and are chosen since panel $\mathrm{E}$ is subjected to the maximum bending loads. Again, good agreement is seen up until buckling is predicted at the weld lands in the analysis, at approximately $74 \% P_{c l}$, with the exception of LVDT \#3 that deviates from the test at about $60 \% P_{c l}$. The membrane and bending strains around the circumference of the TA at the top and bottom of the TA are shown in Figs. 26 and 27, respectively, for LS18 at $69.3 \% P_{c l}$. Very good agreement for membrane strains is seen in the figures where only a few points deviate from the test results by more than $5 \%$, and decent qualitative agreement is seen for the bending strains that are nearly zero at most locations.

Test and analysis contours of the ETTA2 LS18 axial displacements at $69.3 \%$ of $P_{c l}$ are shown in Fig. 28, and represents the load shortly before the analysis predicts the first weld land buckling. Good test and analysis agreement is seen for the axial displacements that are within 10\%. Radial displacement contours for various load levels of LS18 are shown in Figs. 29-31 where good test and analysis qualitative agreement is observed in the contours prior to predicted weld land buckling. However, agreement is not as good in the $\mathrm{D} / \mathrm{E}$ and $\mathrm{E} / \mathrm{F}$ weld lands, where larger inward deformations developed in the analysis that are about twice that observed in the test for the E/F weld land. The larger deformations observed in the predicted contour plots could be a contributing factor to the discrepancies seen in the end-shortening, radial displacement and strain results previously reported. The response of the weld lands in the analysis likely leads to the significant discrepancy during the buckling events. The analysis predicts buckling of the 
E/F weld land (at approximately $74 \% P_{c l}$ ) followed later by buckling of the $\mathrm{D} / \mathrm{E}$, whereas the test exhibited a single buckling event that involved both of the $\mathrm{E} / \mathrm{F}$ and $\mathrm{D} / \mathrm{E}$ weld lands simultaneously at approximately $82 \% P_{c l}$. Despite the buckling load, event discrepancies, and slightly lower post-buckled load, the baseline model predicts the radial contours at maximum load just prior to global buckling closely as seen in Fig. 31. The minor discrepancies seen in the figure are that the analysis predicts larger deformations in the weld lands, and more pocket buckling at the bottom of panels $\mathrm{E}$ and F. Both the analysis and the test show widespread and well-developed pocket buckling in panels $\mathrm{C}$ and $\mathrm{D}$ (the lightly-stiffened panels). These discrepancies could be indications that slight variations in the load introduction are developing at higher loads, particularly with the pocket buckling developing at the bottom of the panels in the predicted response.

In this section, numerous discrepancies between test and analysis have been presented. In particular, ETTA1 demonstrated differences in the development of nonlinear response of the end-shortening and average strain curves, differences in the development of pocket buckling adjacent to the weld lands, differences in the radial displacements due to pressurization (especially at the mid-length of the weld lands), differences in the strains at higher load levels, and difference in the buckling load, $P_{c r}$. The test and analysis results from ETTA2 had better agreement than ETTA1, but discrepancies were observed in the end shortening under pressurization, the buckling load and mode, and the bending response (e.g., strains). Because of the various discrepancies observed between test and analysis, a sensitivity study to examine the effects of modeling on the analysis results was conducted.

\section{Sensitivity Study}

\section{A. Modeling Approach}

As described in the previous section, several discrepancies were identified between the baseline predictions and measured results for both ETTA1 and ETTA2. In order to address the discrepancies a sensitivity study was conducted to determine the effects of various modeling assumptions on the predicted response, and included modifications to the TA models as well as the simulators. Results from modified simulator models are presented in Ref. 6, and are not discussed in detail herein. This section focusses on the modifications to the TA models and boundary conditions at the attachment-ring-to-simulator interfaces. The modifications included; Young's modulus, as-built skin and stiffener geometry, boundary conditions, initial geometric imperfection amplitude, fillet details, residual stress, and manipulation of skin stiffness properties to simulate pocket buckling. A summary of the modeling modifications made and their descriptions is listed in Table 2. Analyses were carried out using LS17 loading conditions of 1 psi internal pressure and uniform axial compression. Each modification was applied to the model independently to determine the effect that each refinement had on the response. Most of the modeling refinements were straight forward, such as increasing thickness, changing material properties from isotropic to orthotropic, or reducing the magnitude of the imperfection. However, several of the model refinements were more involved and require a detailed description. In particular, detailed descriptions for fillet modeling, residual stress modeling, and simulated pocket buckling are provided in the following paragraphs.

\section{Fillet details}

Detail features such as fillets were often omitted from models to reduce model complexity. However, these fillet details can provide additional support to the skin and the stiffeners, increase the effective axial stiffness of the cylinder, and affect the predicted buckling response. In this study, representations of the fillets were added to the model by increasing local stiffener thickness near the intersection between the stiffeners and skin, and at the intersection between stiffeners to simulate the effects of the fillet details. To do so, a shell thickness tuning approach, based on correlations between two-dimensional (2D) shell models and three-dimensional (3D) solid models, was used to develop an equivalent set of shell thickness properties to represent the fillets.

Shell and solid models were developed for selected TA subcomponents. The ETTA1 areas that were used to create the shell model and solid models are identified in Fig. 32, one for the acreage and one for the weld land. The shell subcomponent models were generated in Abaqus and used the same modeling assumptions and mesh refinement used in the full TA model, so that the thickness properties derived from the tuning process could be transferred directly to the TA model. Corresponding solid models were generated in Abaqus using the C3D10 element, and included detailed representations of all the as-designed fillet features (recall Fig. 1). To simplify generation of the subcomponent models, the cylinder curvature was ignored and the examined regions were assumed to be flat. The solid models were refined until converged models were obtained. Linear bifurcation buckling and nonlinear static analyses were performed for uniform axial compression. An iterative process was used to adjust the shell model thickness properties in the fillet locations, until the shell model eigenloads and modes and axial stiffness response match the corresponding solid model results to within $\pm 3 \%$, on average. The shell models with fillet representations are referred to as "thickness-tuned" 
herein. As-designed fillet radii ranged from 0.125 inches to 0.31 inches at the intersection between the skin and stiffeners, and 0.450 inches to 0.500 inches for the node regions (stiffener-to-stiffener intersections). Adjusted shell thicknesses derived using this tuning approach ranged from 0.016 inches to 0.078 inches for the stiffener base fillets and 0.063 inches to 0.144 inches for the node fillets.

\section{Residual stresses}

Recall that the panels used in ETTA1 and ETTA2 were formed to OML radii of 168 inches, however, the arcwidth of each panel was approximately 130 inches, corresponding to 1/8 of the circumference of a 165.5-in-radius cylinder (the as-designed final radius). Therefore, when the eight panels A through $\mathrm{H}$ were welded together, they formed a $354.6^{\circ}$ arc with a 168 -inch radius and a 15.7-inch gap between panels $\mathrm{H}$ and $\mathrm{A}$ at the final weld location. To complete the cylinder welding process, the edges of panels $\mathrm{H}$ and A were pulled together and the final weld was made.

It was hypothesized that the pulling together of the panel edges could generate residual stress throughout the cylinder and affect the response. These stresses were determined using an analysis whereby the eight ETTA1 panels were modeled as a large curved panel, with the 168-inch OML radius and a single gap at the location of the final weld. The axial free edges of the panel were brought together in a nonlinear static analysis to be coincident, and to have the same tangent to form a closed shell with a 165.5-inch OML radius. Stress values were extracted from the analysis and prescribed as a residual stress (referred to as a stress initial condition in the Abaqus code) in the TA models. Stresses ranged from about $-750 \mathrm{psi}$ at the free edge of the circumferential stiffeners to about 10 psi in the skin.

Additionally, local residual stresses associated with the friction stir welding process itself were introduced. Residual stress was based on work performed in-house at NASA Langley Research Center on Al-Li 2195 alloy where residual stress measurements were made using a drilled-hole stress-relief method. Axial stresses were relatively small, and therefore were not included. An average circumferential compression stress of 7000 psi was assumed, and was applied to the elements in the weld lands of the models. The residual stress model refinements attempted to address the presence both residual stresses, but only residual stress in the hoop (circumferential) direction was included since the axial stresses were very small. The first model included only the residual stress due to the cylinder being formed from the larger radius to the final radius, and is referred to herein as the RS1 model. The second model added the residual stress associated with the friction stir welding process to the weld lands, and is referred to herein as the RS2 model.

\section{Simulated pocket buckling}

It was hypothesized that the pronounced nonlinear load versus axial strain response in ETTA1 (see Fig. 13) was due to extensive skin pocket buckling. However, the ETTA1 FEM did not exhibit the same pocket buckling response or load versus axial strain response. In particular, ETTA1 exhibited significant skin buckling in pockets adjacent to the weld lands and occurred at a relatively low load level. In contrast, the FEM predicted buckling to occur more towards the ends of the cylinder and in the interior of the individual panels and at a higher load level than what was observed in the test. Thus, a model was developed to simulate the effects of the skin buckling adjacent to the weld lands to determine if the discrepancy in the nonlinear load versus axial strain response was due to differences in the pocket buckling response. The effects of pocket buckling were simulated in the model by assuming a material stiffness reduction, similar to the stiffness reduction seen when a shallow curved panel buckles. This stiffness reduction was modeled by using a nonlinear material model in the skin pockets adjacent to the weld lands. The stiffness was reduced at two stress levels in the stress-strain relationship of the material. The first stiffness reduction was introduced at the average axial stress level associated with $P / P_{c l}$ equal to 0.37 , or at a stress of 4500 psi. The second stiffness reduction was introduced at a stress level of $24,500 \mathrm{psi}$ and strain of $0.003636 \mathrm{in}$./in., and correspond to a $P / P_{c l}=0.49$. This trilinear stress/strain material response was applied to all of the skin pockets in the first three columns adjacent to the weld lands, and is referred to herein as the simulated pocket buckling (SPB) model.

\section{B. Results}

Selected results for the sensitivity study conducted on ETTA 1 are presented in this section. Average strain response in ETTA1 was examined, in lieu of end shortening due to the aforementioned difficulties with the LVDTbased displacement measurement data, as it is the first global measure of the TA performance. As previously mentioned, the test data indicated that pocket buckling initiated adjacent to the weld land and the baseline analysis indicated that pocket buckling initiated near the center of the panel. The SPB was used to examine to simulate earlier pocket buckling in the analysis. Recall from Fig. 13 that the measured average strain data exhibited nonlinear behavior at a lower load than the analysis, beginning at a normalized load level less than 0.6, and then exhibiting more pronounced nonlinearity at a normalized load level of about 0.8. The average strain in ETTA1 is compared in Fig. 33 to the DIC data for the SPB model under 1.0 psi internal pressure and uniform compression. Examination of Fig. 33 
indicates that reducing the stiffness of the skin pockets adjacent to the weld land to simulate pocket buckling does lead to nonlinear behavior similar to the test data. The increased nonlinearity of the analysis indicates that the modification was more severe than necessary to simulate the test response, but in general the results suggest that achieving pocket buckling adjacent to the weld lands in the analysis would better represent the nonlinear end shortening and axial strain response observed during the test.

Again, examining the average strain response, consider the results for the model that incorporated orthotropic properties shown in Fig. 34 that are compared to both DIC and baseline analysis results. Note that changing from isotropic to orthotropic properties increased the overall stiffness slightly, but the two analysis models exhibit similar response, with nonlinear response beginning at a significantly higher normalized load level than the test. In general, similar response was seen for the other model refinements, with results being of similar values to the baseline model or less compliant than the baseline model (e.g., node tuned and increased thickness models). However, some changes in the predicted response were observed for the RS2 refinement, where the average strain curves obtained a slightly different axial strain level during the pressurization to $1.0 \mathrm{psi}$, as seen in Fig. 35. Additionally, the axial strain distribution around the circumference of the cylinder changed significantly and showed better overall correlation with the measured strains, as shown in Figs. 36 and 37.

\section{Conclusions}

Selected results from a recent analysis model development and test and analysis correlation effort on two fullscale, 27.5-foot-diameter, Al-Li 2195, integrally stiffened cylinders were presented. The effects of selected modeling assumptions and approaches were discussed, and results from a modeling sensitivity study were presented. It was found that simplified FEMs, that assume nominal TA geometry and material properties, can predict the overall response characteristics well. However, several discrepancies in the test and analysis results were observed. A sensitivity study was performed to determine the effects of several modeling assumptions and address the observed discrepancies. The results from the study indicated that the evolution of local skin pocket buckling and the presence of residual stresses due to the manufacturing process can have a significant influence on the predicted buckling response of the cylinders considered. In particular, it was found that skin pocket buckling adjacent to the axial weld lands in the TA led to a nonlinear load versus axial strain response at lower load levels than predicted. The effects of pocket buckling were simulated in a FEM, and resulted in similar load versus axial strain response characteristics as seen in the test. In addition, it was found that the modeling of residual stresses due to panel forming and welding can have a significant effect on the local deformations and strains throughout the TA.

\section{References}

${ }^{1}$ Weingarten, V. I., Peterson, J. P., and Seide, P., "Buckling of Thin-Walled Circular Cylinders," NASA Space Vehicle Design Criteria, NASA SP-8007, September 1965 (Revised 1968).

${ }^{2}$ Weingarten, V. I., and Seide, P., "Buckling of Thin-Walled Truncated Cones," NASA Space Vehicle Design Criteria, NASA SP-8019, September 1968.

${ }^{3}$ Weingarten, V. I., and Seide, P., "Buckling of Thin-Walled Doubly Curved Shells," NASA Space Vehicle Design Criteria, NASA SP-8032, August 1969.

4،"Isogrid Design Handbook," NASA CR-124075, February 1973.

${ }^{5}$ Hilburger, M. W., Lindell, M. C., Lovejoy, A. E., Haynie, W. T., Waters, W. A., Jr., Gardner, N. W., and Matarese, R. A., "Buckling Analysis and Test Results from Selected 8-Foot-Diameter Integrally-Stiffened Al-Li Cylinder Test Articles," NASA TM-2018-000000, 2018. (In preparation)

${ }^{6}$ Lovejoy, A. E., Hilburger, M. W., Haynie, W. T., Satyanarayana, A., Gardner, N. W., Roberts, M. G., Norris, J. P., and Thornburgh, R. P., "Buckling Analysis and Test Results for Full-scale 27.5-Foot-Diameter Integrally-Stiffened Al-Li Cylinder Test Articles," NASA TM-2018-000000, 2018. (In preparation)

${ }^{7}$ Thornburgh, R. P., and Hilburger, M. W., "Design of the Space Shuttle External-Tank-Derived Test Articles for the Shell Buckling Knockdown Factor Project,” NASA TM-2011-217074 and ARL-TR-5485, March, 2011.

${ }^{8}$ https://www.3ds.com/products-services/simulia/products/abaqus (valid as of May 1, 2017)

\section{Acknowledgments}

This work was conducted as part of the NASA Engineering and Safety Center (NESC) Shell Buckling Knockdown Factor Project, NESC Assessment \#:07-010-E. 
Table 1. ETTA1 and ETTA2 Acreage Orthogrid Design Values.

\begin{tabular}{|c|c|c|}
\hline Dimension & $\begin{array}{c}\text { Lightly Stiffened } \\
\text { (ETTA1, ETTA2) }\end{array}$ & $\begin{array}{c}\text { Heavily Stiffened } \\
\text { (ETTA2) }\end{array}$ \\
\hline$t$ (in.) & 0.093 & 0.089 \\
\hline$t_{s}$ (in.) & 0.086 & 0.105 \\
\hline$b_{s}$ (in.) & 10.832 & 5.416 \\
\hline$t_{r}$ (in.) & 0.100 & 0.125 \\
\hline$b_{r}$ (in.) & 15.318 & 15.318 \\
\hline$H$ (in.) & 1.050 & 1.300 \\
\hline
\end{tabular}


Table 2. Sensitivity study modeling refinements.

\begin{tabular}{|c|c|}
\hline Refinement & Description \\
\hline Nodes and fillets* & $\begin{array}{l}\text { Include increased thickness in elements at the stiffener intersections, and at the } \\
\text { intersection of the stiffeners with the skin. }\end{array}$ \\
\hline Attachment ring variation $1 *$ & $\begin{array}{l}\text { Replace the laminated shell approach attachment region with discrete shells for } \\
\text { the attachment ring webs, discrete shells for the test article, springs for the } \\
\text { potting material between the test article and rings, and beams for the bolts } \\
\text { through the attachment rings and test article. }\end{array}$ \\
\hline Attachment ring variation $2 *$ & $\begin{array}{l}\text { Replace the laminated shell approach attachment region with rings of stiff beams } \\
\text { to maintain the circular cross-section along the attachment region, while allowing } \\
\text { the test article to strain axially within the attachment region. }\end{array}$ \\
\hline Attachment ring variation $3 *$ & $\begin{array}{l}\text { Same as attachment ring variation } 2 \text {, but having the ring of beams at the "top" of } \\
\text { the attachment rings, the part of the webs adjacent to the test region, softened to } \\
\text { allow radial expansion to represent the test article deforming the potting. }\end{array}$ \\
\hline Orthotropic material $* *$ & $\begin{array}{l}\text { Replace the isotropic test article material with orthotropic material properties. } \\
\text { Used Young's modulus of } 11.4 \mathrm{Msi} \text { axially, compression modulus, and } 10.8 \mathrm{Msi} \\
\text { circumferentially, tension modulus. }\end{array}$ \\
\hline $\begin{array}{l}\text { Simulated pocket buckling } \\
\text { (SPB) in pockets adjacent to } \\
\text { weld lands** }\end{array}$ & $\begin{array}{l}\text { Replace the linear material in the three columns of pockets adjacent to the weld } \\
\text { lands with trilinear material properties, a three-part stress/strain curve was } \\
\text { defined with a reduced stress for yielding, to represent stiffness reduction of the } \\
\text { region adjacent to the weld land associated with pocket buckling. }\end{array}$ \\
\hline Increased shell thickness** & $\begin{array}{l}\text { Increased the shell thickness of the test article gauges by adding } 0.005 \text { inches, the } \\
\text { manufacturing tolerance, to account for increased thickness that was observed on } \\
\text { some sparsely made measurements of ETTA1. }\end{array}$ \\
\hline $\begin{array}{l}\text { Reduced imperfection } \\
\text { amplitude** }\end{array}$ & $\begin{array}{l}\text { Reduce the amplitude of the imperfection to } 80 \% \text { of the measured imperfection } \\
\text { to represent the possibility of the imperfection changing during installation in the } \\
\text { stack. }\end{array}$ \\
\hline $\begin{array}{l}\text { Tension/Compression at } \\
\text { weld lands*** }\end{array}$ & $\begin{array}{l}\text { Apply load sets at the weld lands to reduce the strain in the weld lands (added } \\
\text { tension) and increase the strains in the column of pockets adjacent to the weld } \\
\text { lands (compression) using sinusoidal load distribution, introducing no net load to } \\
\text { the test article. }\end{array}$ \\
\hline Residual stress $1(\mathrm{RS} 1)^{* * *}$ & $\begin{array}{l}\text { Add residual stress associated with the forming process. Residual stress was } \\
\text { determined by running an analysis modeling the forming process from } 168 \text {-inch } \\
\text { radius to } 165.5 \text {-inch radius. }\end{array}$ \\
\hline Residual stress $2(\mathrm{RS} 2) * * *$ & $\begin{array}{l}\text { RS1 with additional stress added at the weld lands to represent the residual stress } \\
\text { introduced by the friction stir welding process. }\end{array}$ \\
\hline $\begin{array}{l}\text { Applied moment on } \\
\text { attachment rings } * * *\end{array}$ & $\begin{array}{l}\text { Apply uniform distributed moment around the attachment rings to introduce } \\
\text { bending that was observed in the simulators adjacent to the attachment rings. }\end{array}$ \\
\hline Simulator strain matching $* * *$ & $\begin{array}{l}\text { Apply pairs of zero-sum loads to the simulators adjacent to the attachment } \\
\text { regions. The pairs of loads were applied on either side of the strain gages on the } \\
\text { simulators, and were generated using combinations of Tchebychev polynomials } \\
\text { to match simulator strains measured during under } 1.0 \text { psi loading in an effort to } \\
\text { modify the interface boundary deformations. }\end{array}$ \\
\hline
\end{tabular}

*Modeling Technique, **Test Article Variation, ***Boundary Conditions 


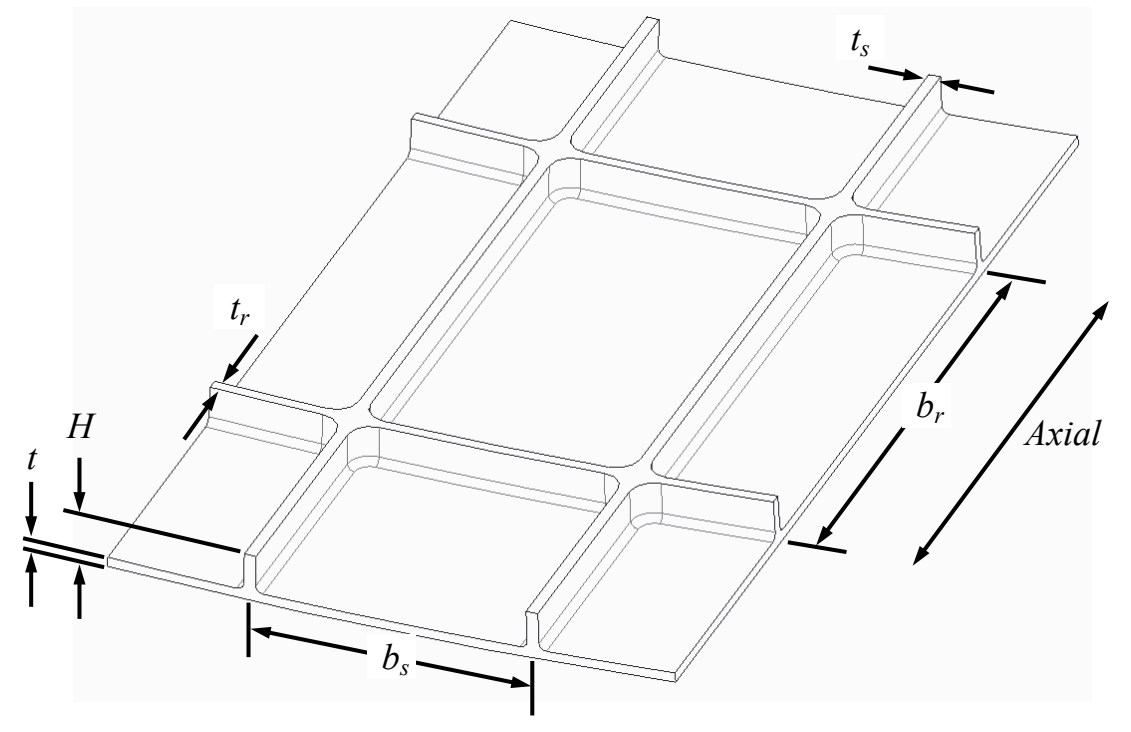

Figure 1. Orthogrid nomenclature.

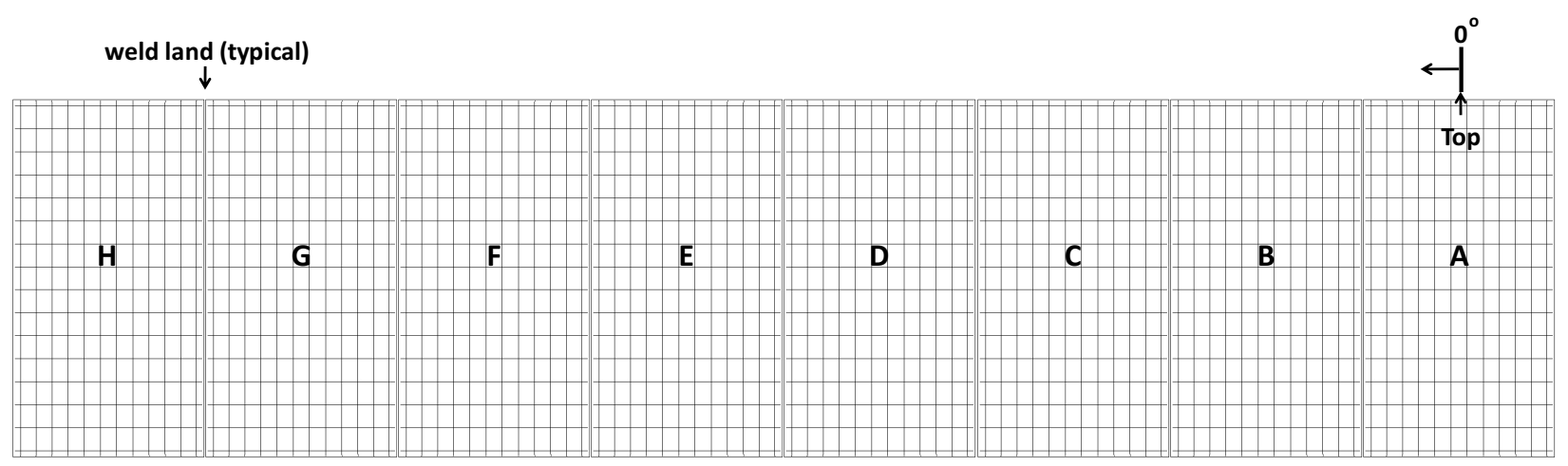

a) ETTA1 panel layout

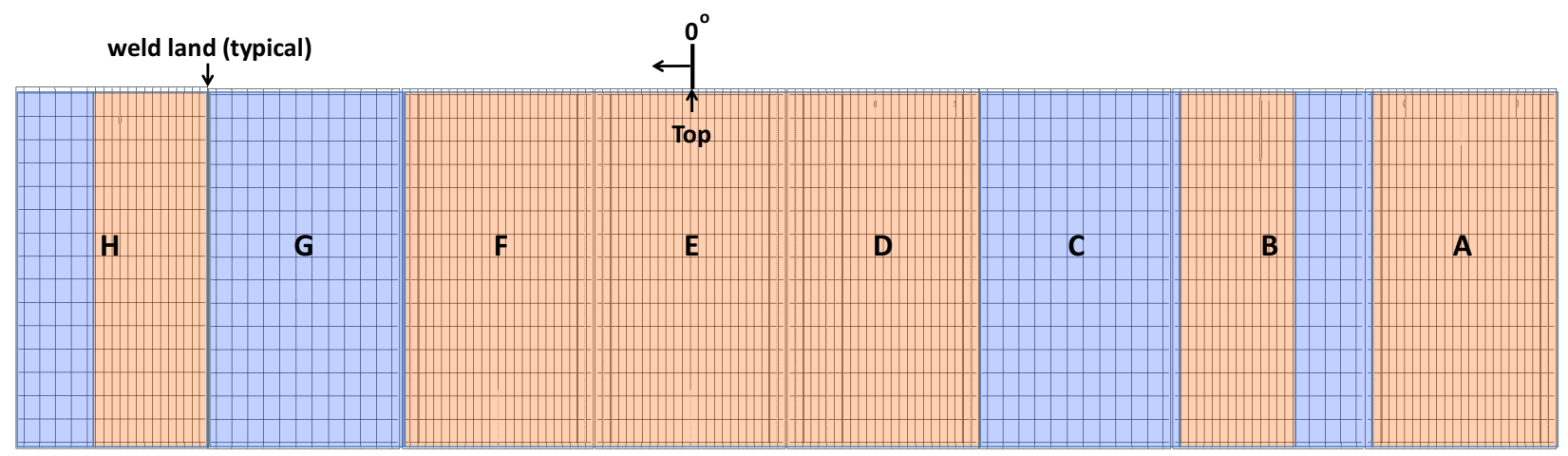

Lightly-Stiffened Acreage

Heavily-Stiffened Acreage

b) ETTA2 panel layout

Figure 2. Full-scale buckling test article panel layouts and stiffener patterns. (viewed from IML)

American Institute of Aeronautics and Astronautics 


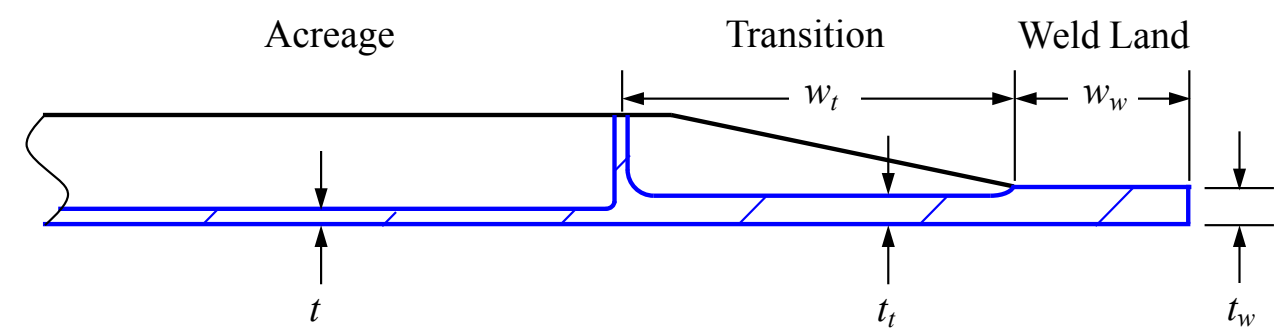

Figure 3. Acreage to weld land transition details.

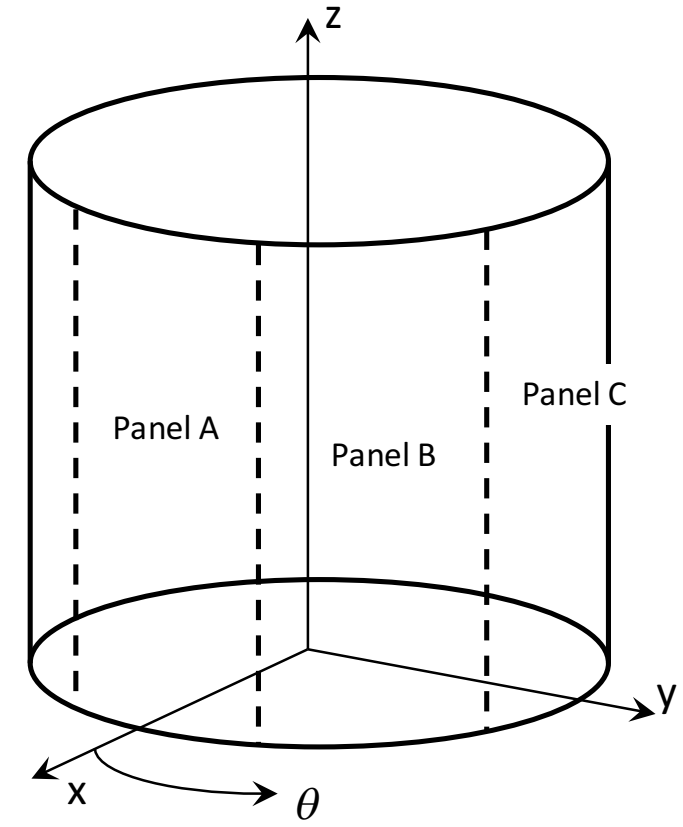

a) ETTA1

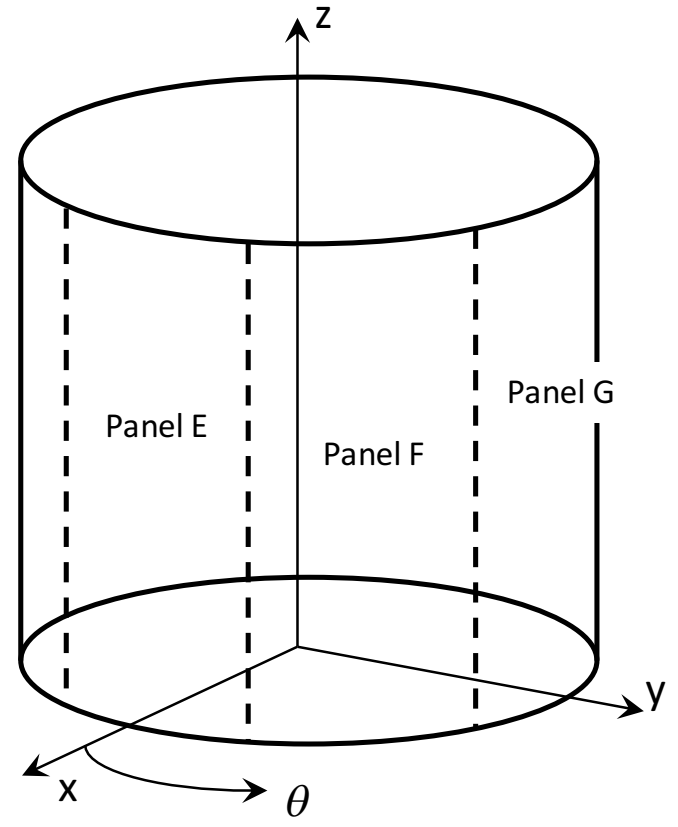

b) ETTA2

Figure 4. Coordinate systems for full-scale test articles. 


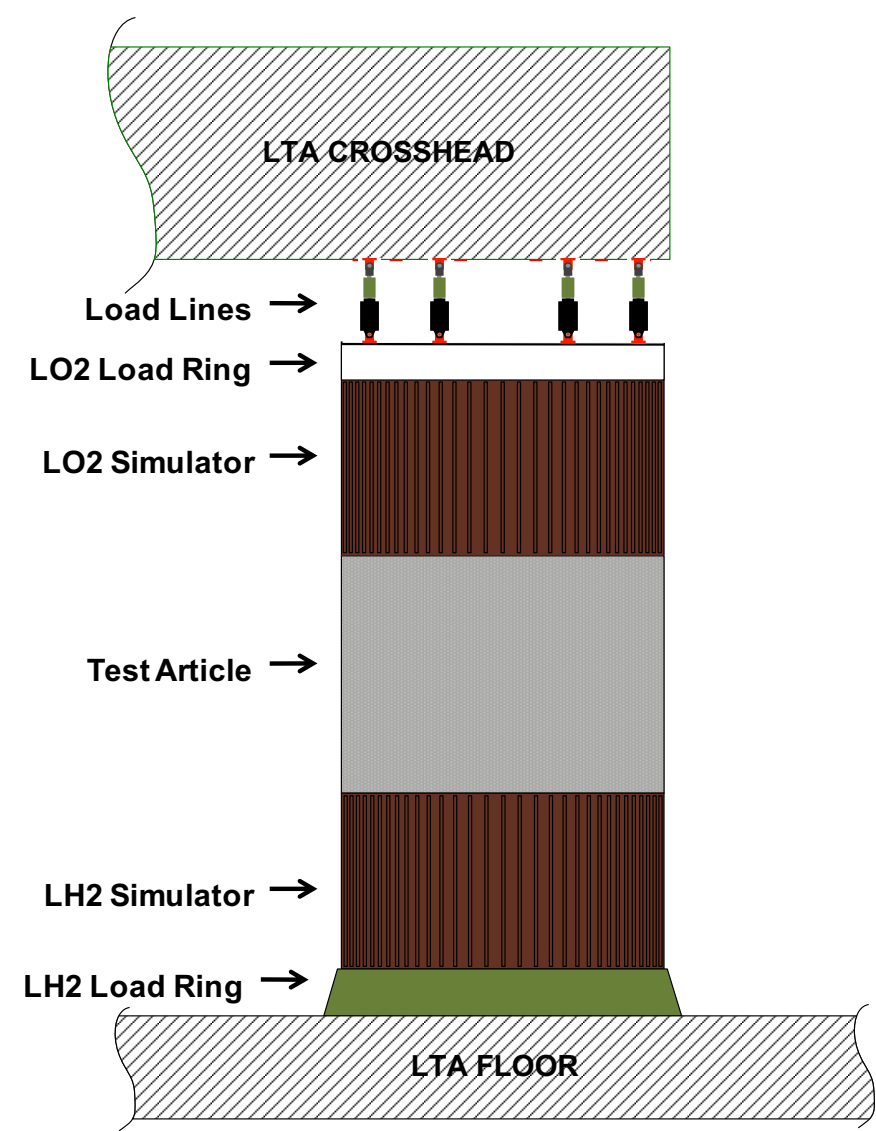

a) Facility schematic

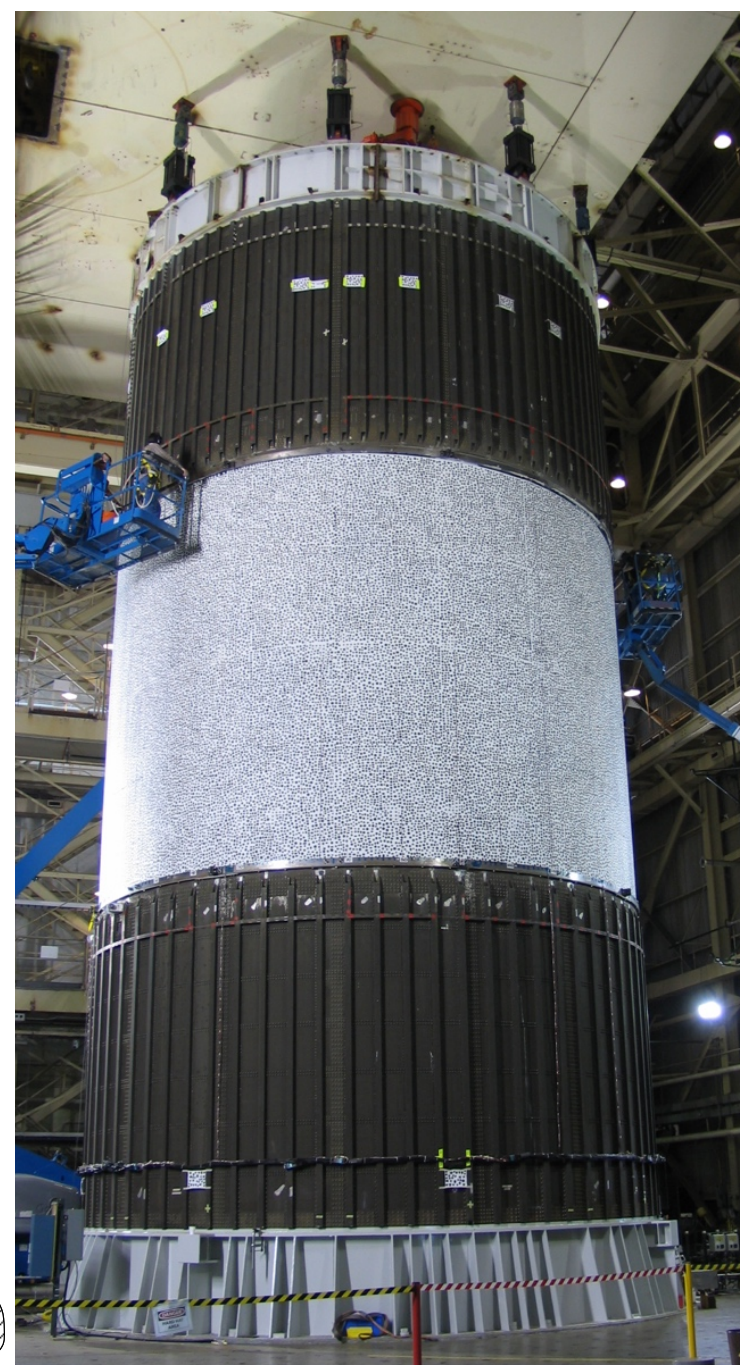

b) ETTA1 stack photo

Figure 5. Full-scale test article facility and stack. 
Top: Adjacent to LO2 Simulator

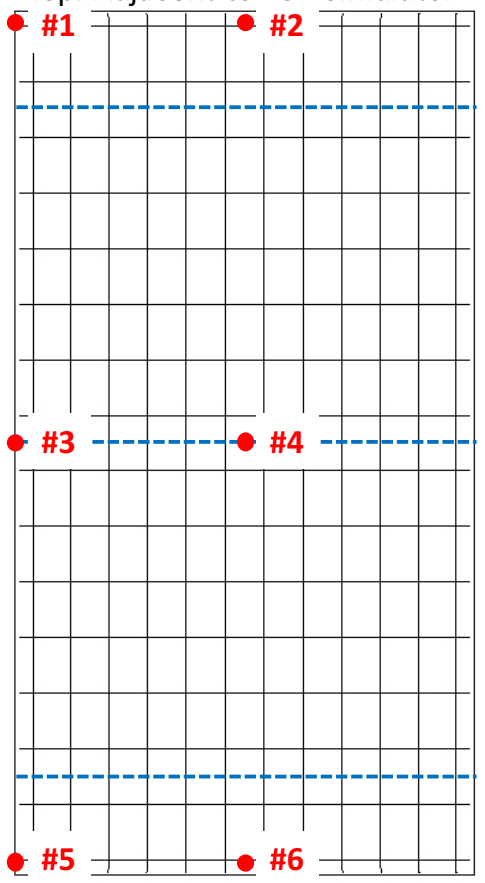

Bottom: Adjacent to LH2 Simulator

Figure 6. Nominal radial LVDT measurement (red numbered) and strain gage trace (dashed line) locations, viewed on IML, for all panels.

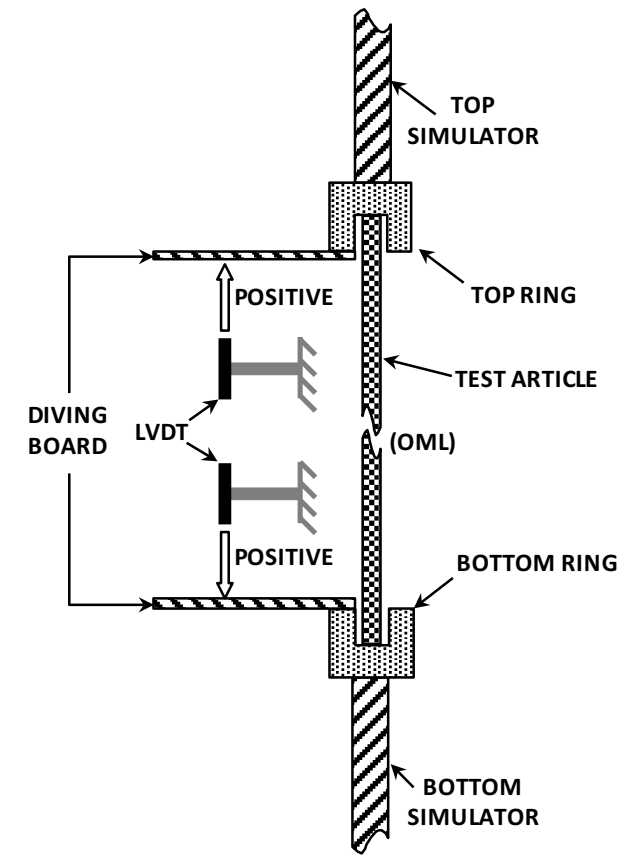

a) Original layout (LS01-LS04)

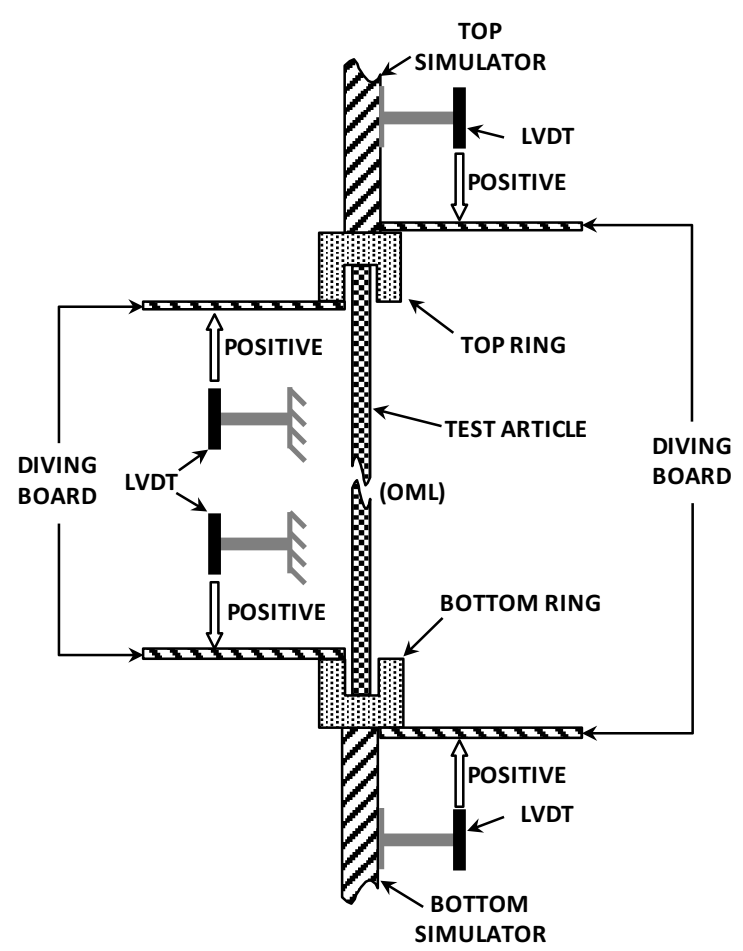

b) Modified layout (LS05-LS17)

Figure 7. ETTA1 axial LVDT mounting schematic.

American Institute of Aeronautics and Astronautics 


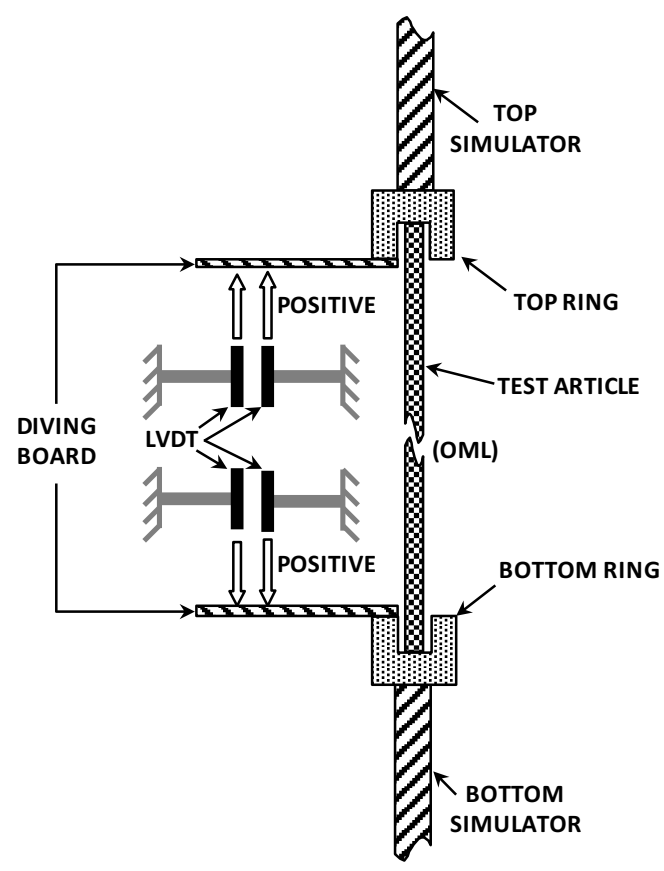

Figure 8. ETTA2 axial LVDT mounting schematic.

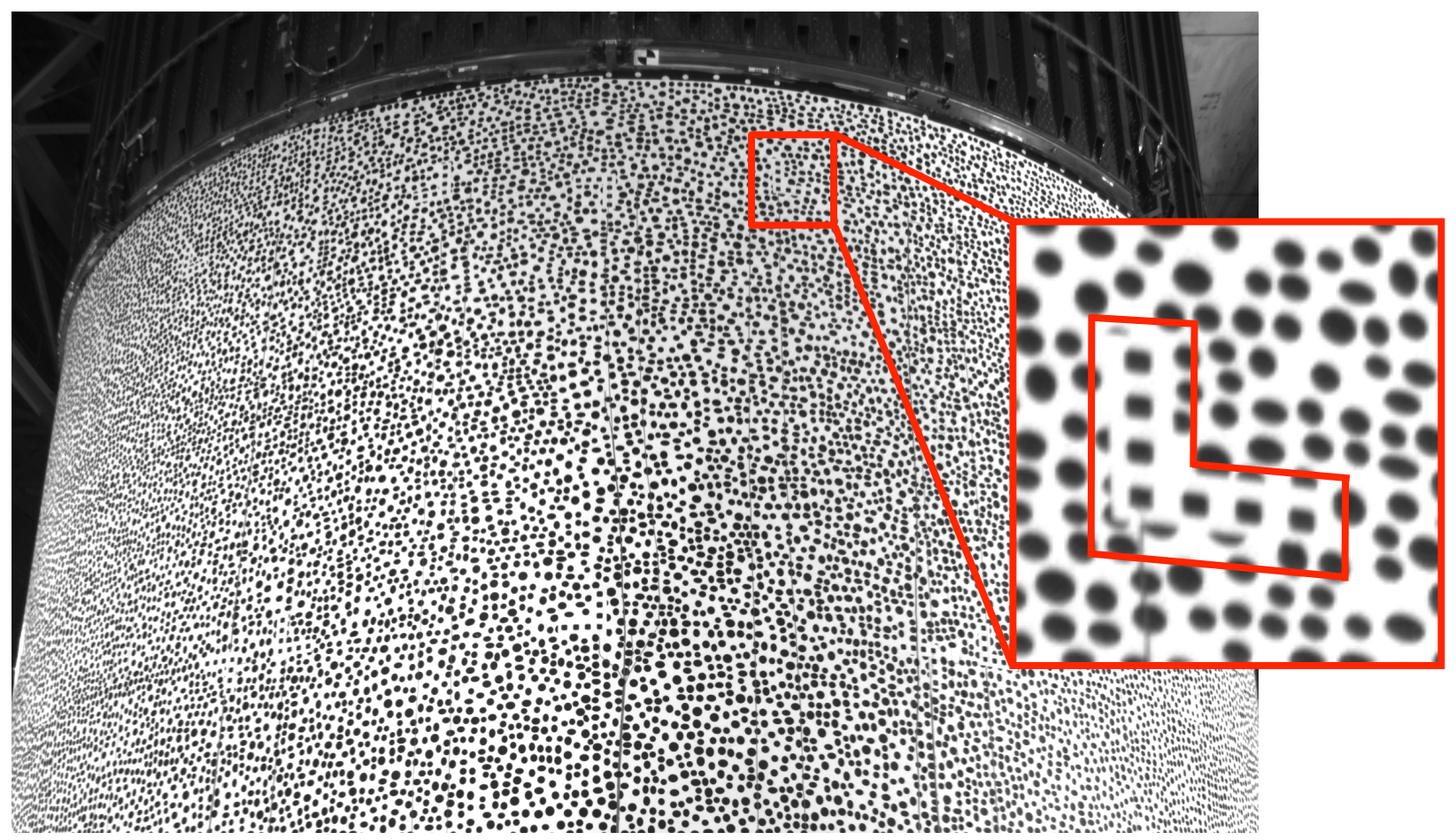

Figure 9. ETTA1 "L" marker for DIC, consisting of square symbols. 


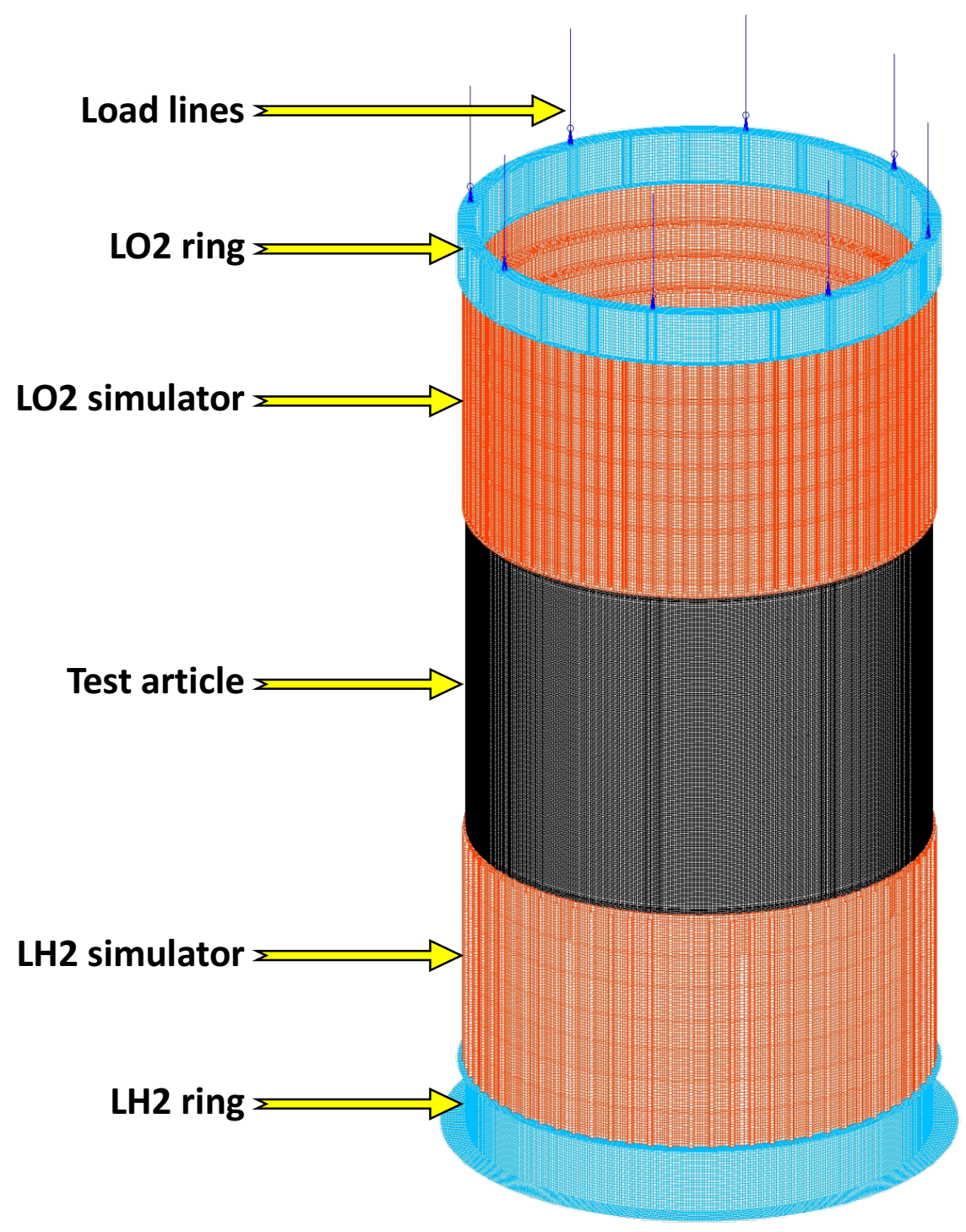

Figure 10. Finite element model of the ETTA stack. 


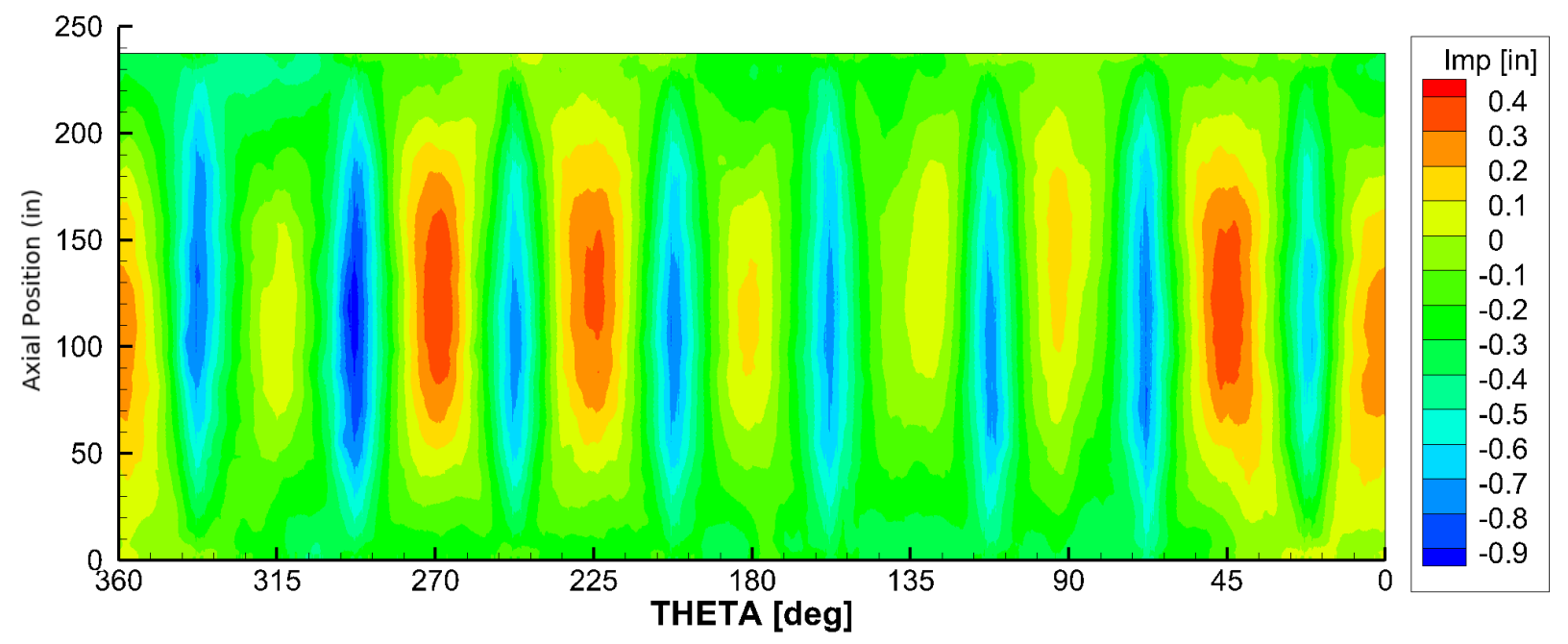

a) ETTA1.

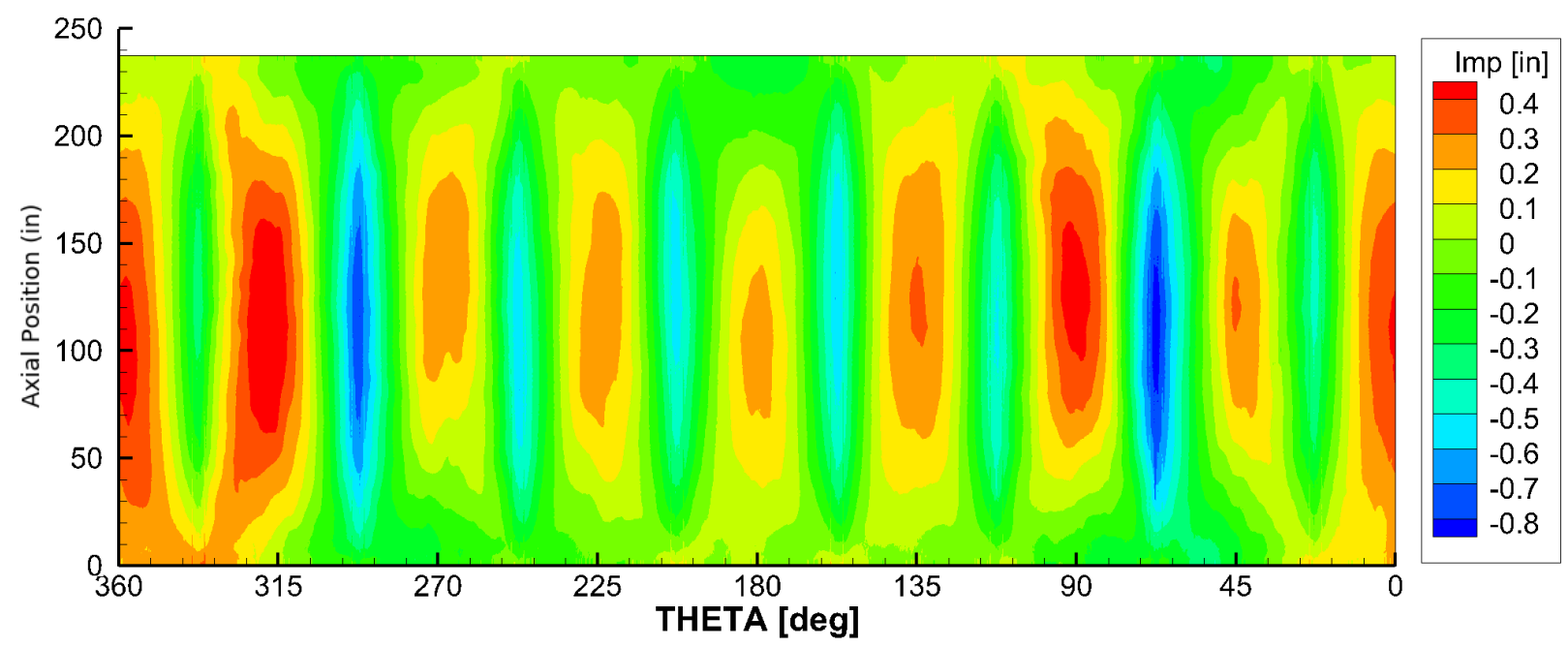

a) ETTA2.

Figure 11. Measured imperfection using structured-light scanning. 


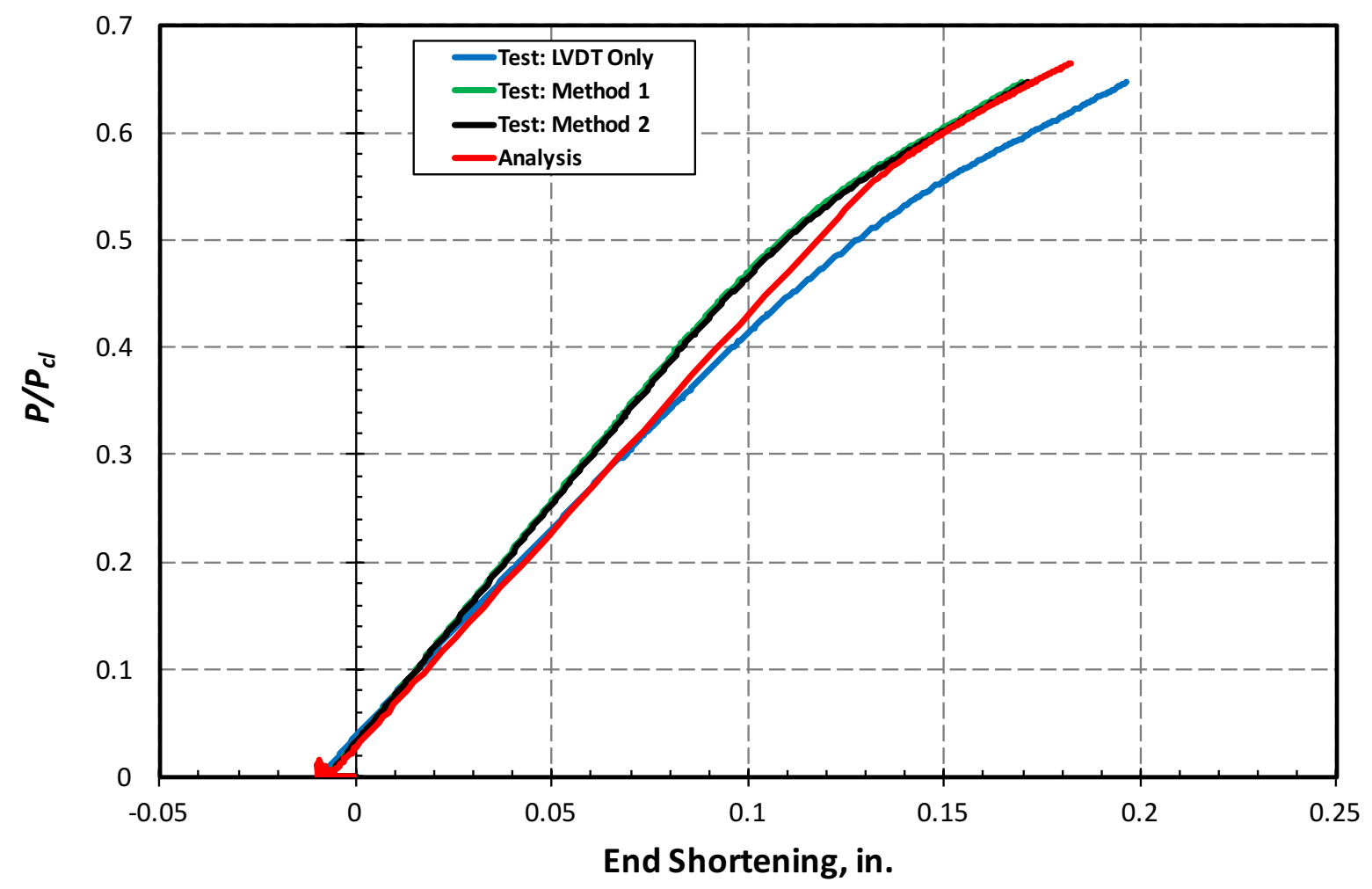

Figure 12. ETTA1 baseline comparison of test and analysis normalized load vs. end shortening, LS17.

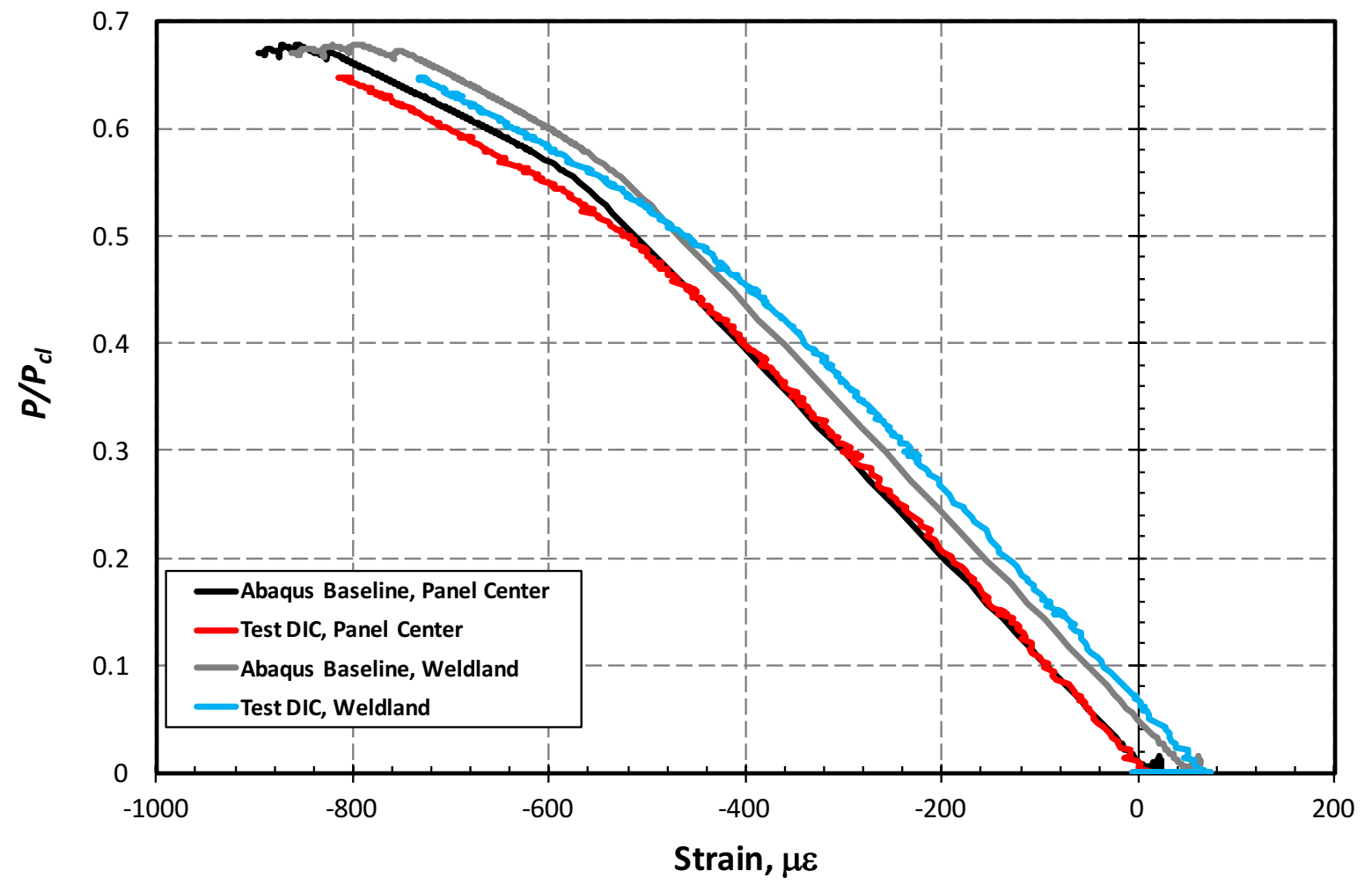

Figure 13. ETTA1 baseline analysis comparison of load factor vs. average strain, DIC "L" markers, LS17. 


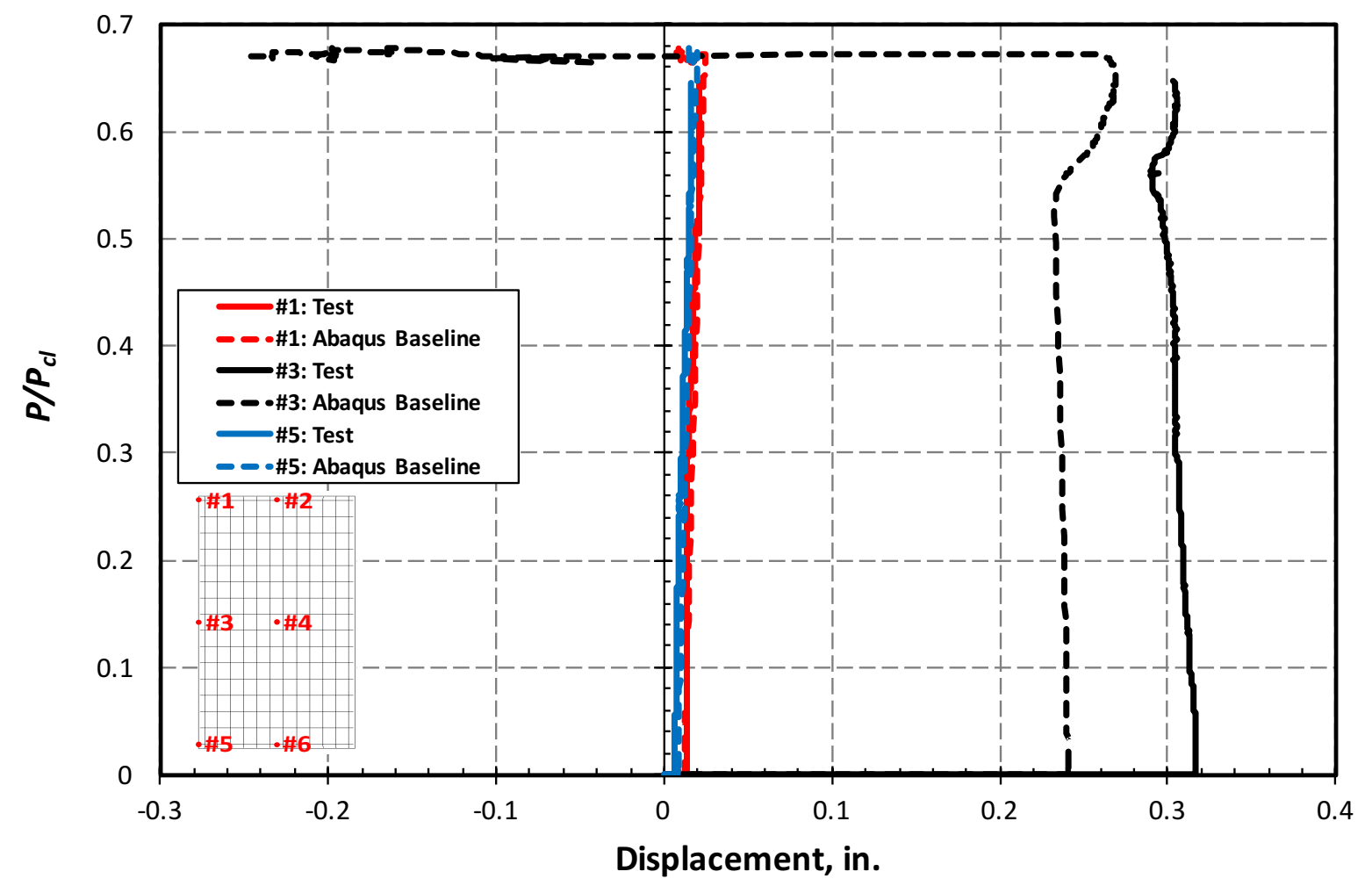

Figure 14. ETTA1 baseline H/A weld land radial displacement comparison, LS17.

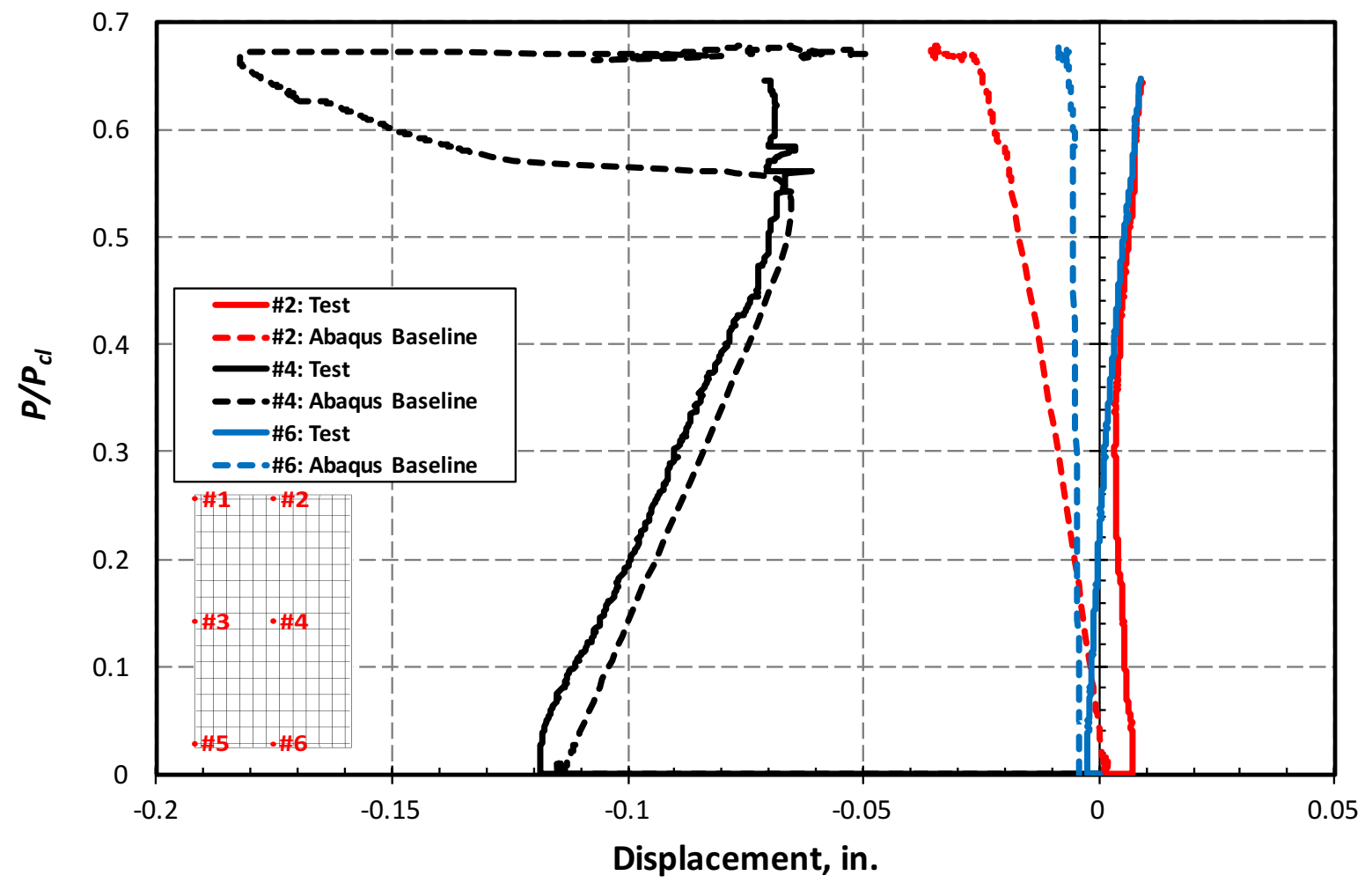

Figure 15. ETTA1 baseline panel H center displacement comparison, LS17. 


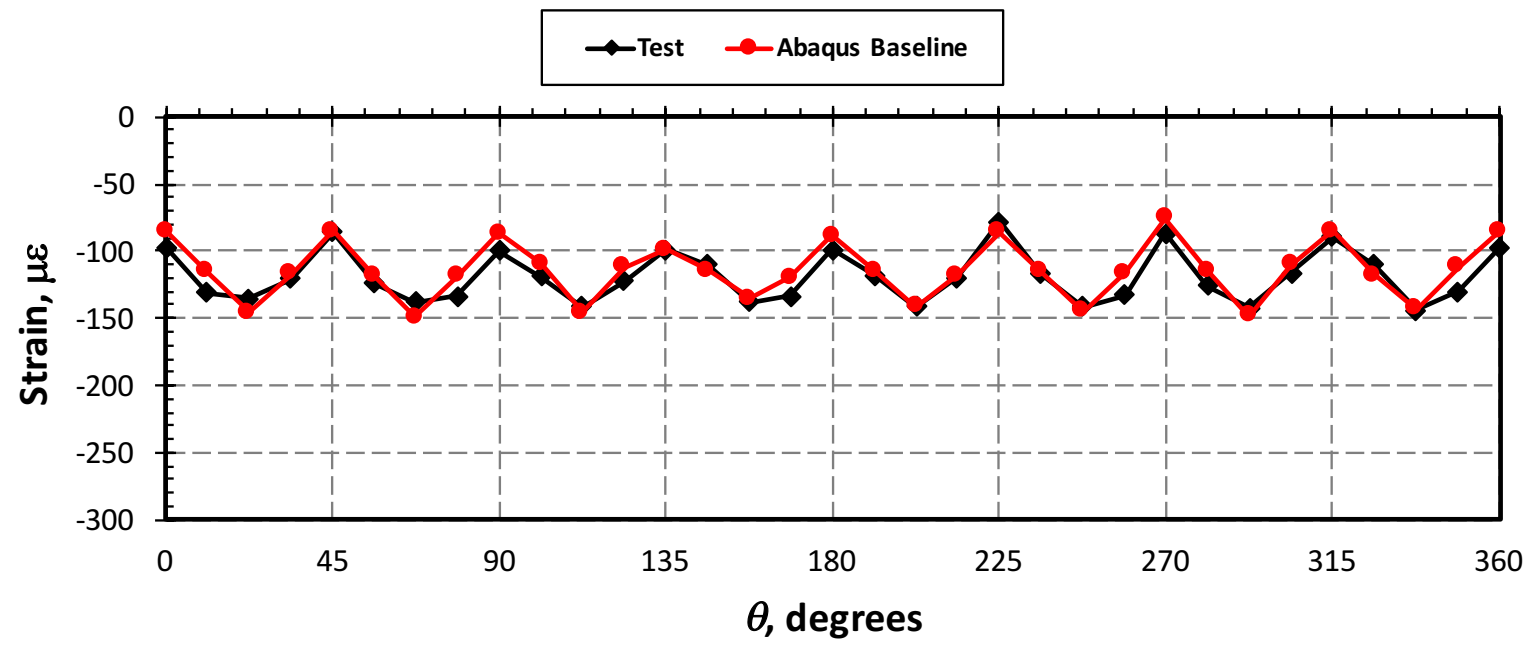

a) Top, near to LO2 simulator

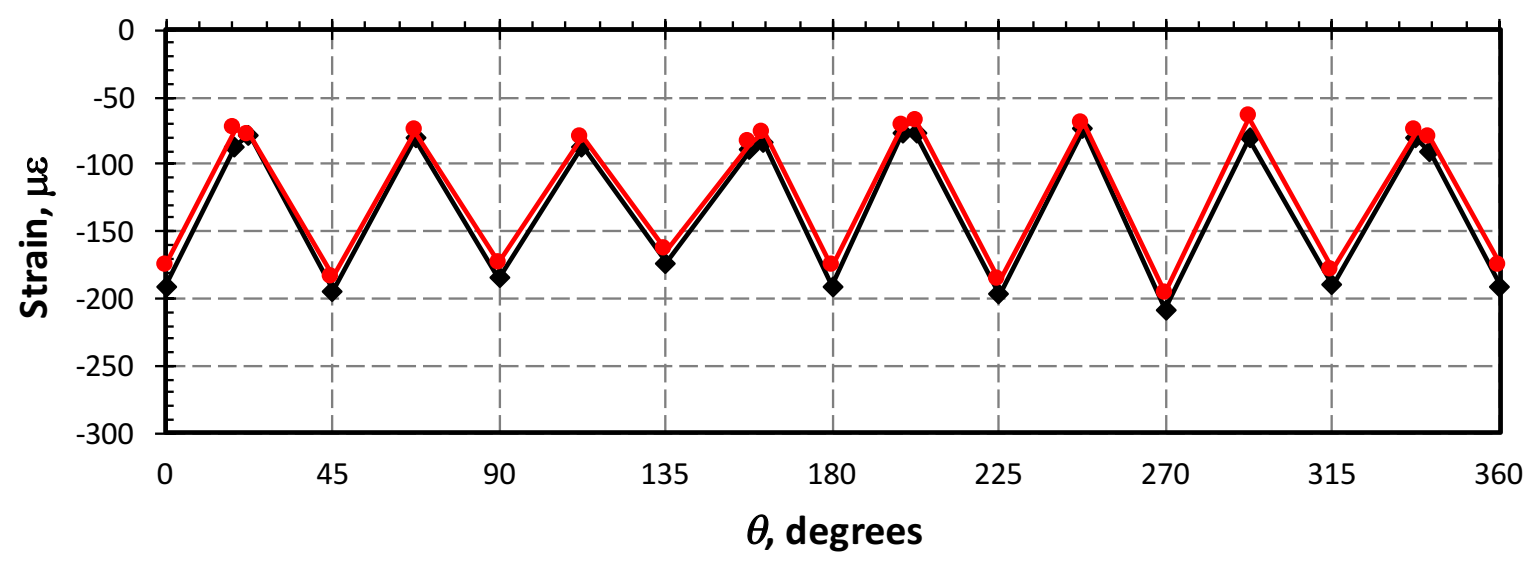

b) Mid-length

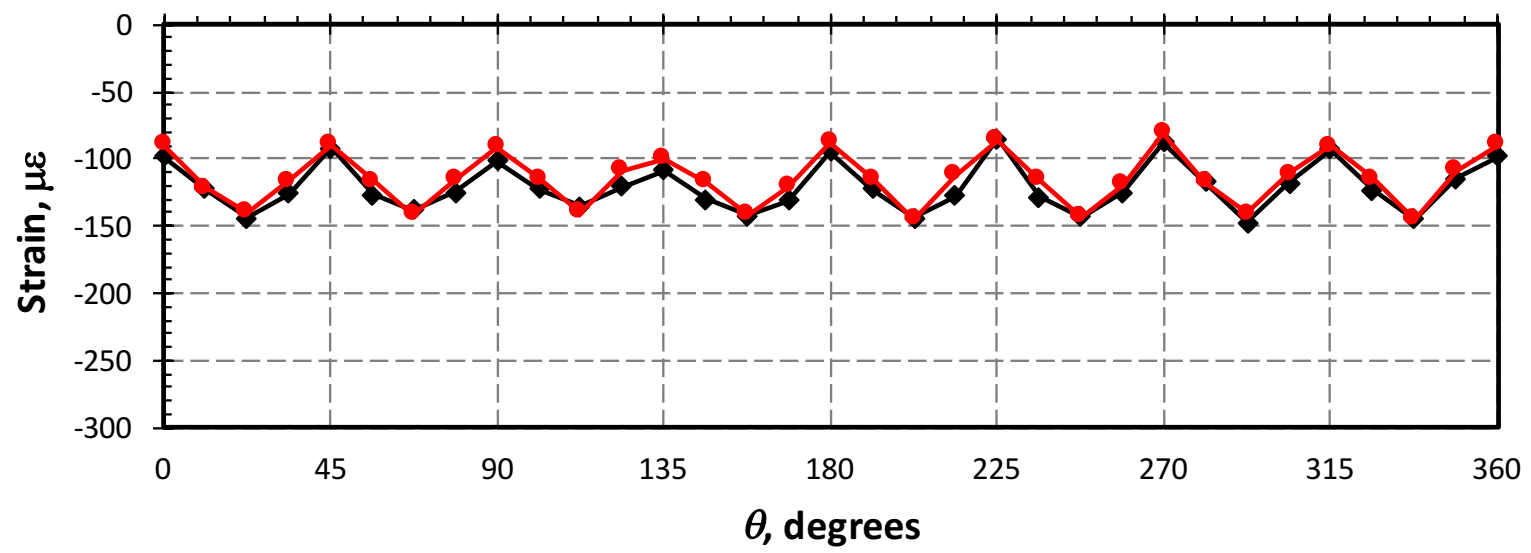

c) Bottom, near to LH2 simulator

Figure 16. ETTA1 baseline analysis comparison of membrane strain, $1.0 \mathrm{psi}$ and $15 \% \boldsymbol{P}_{c l}$. 


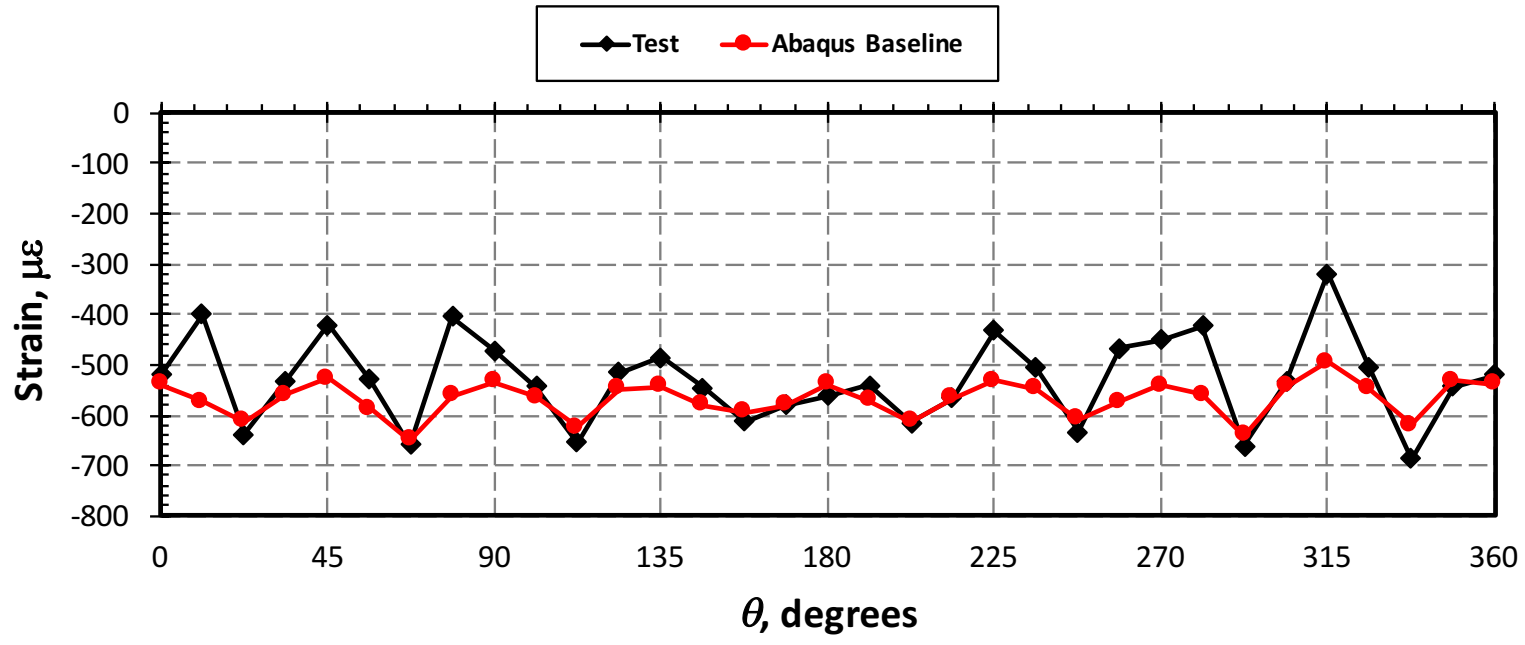

a) Top, near to LO2 simulator

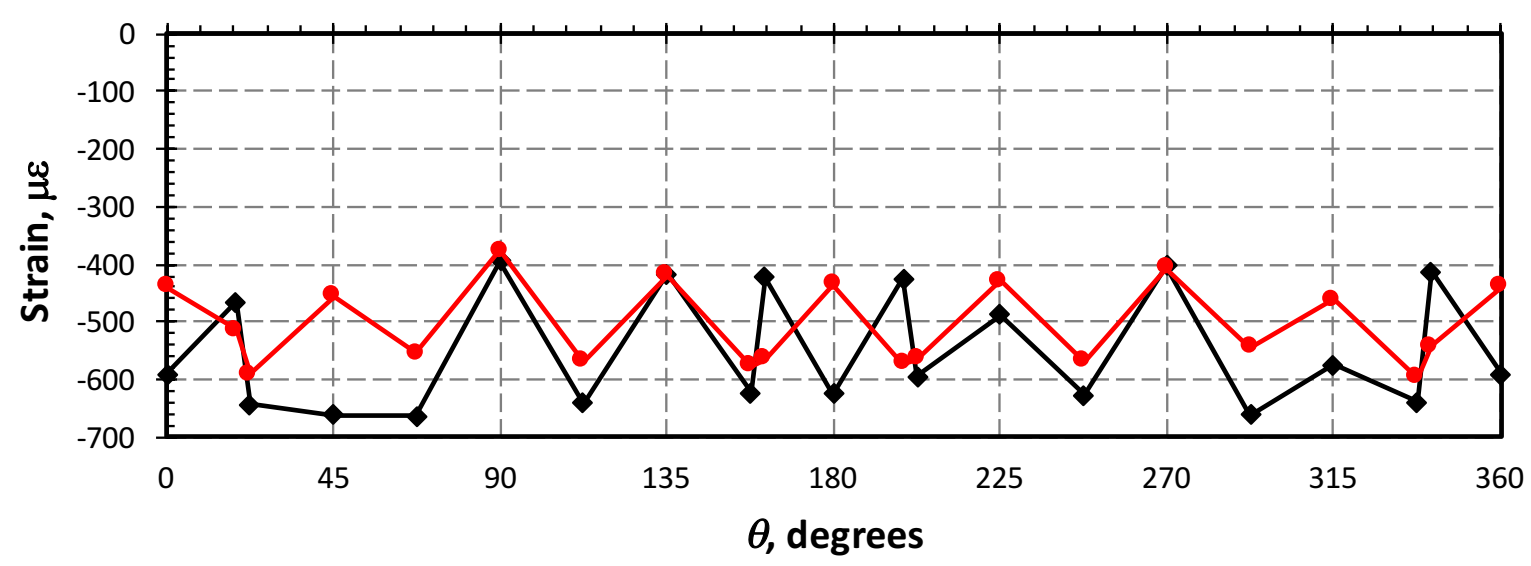

b) Mid-length

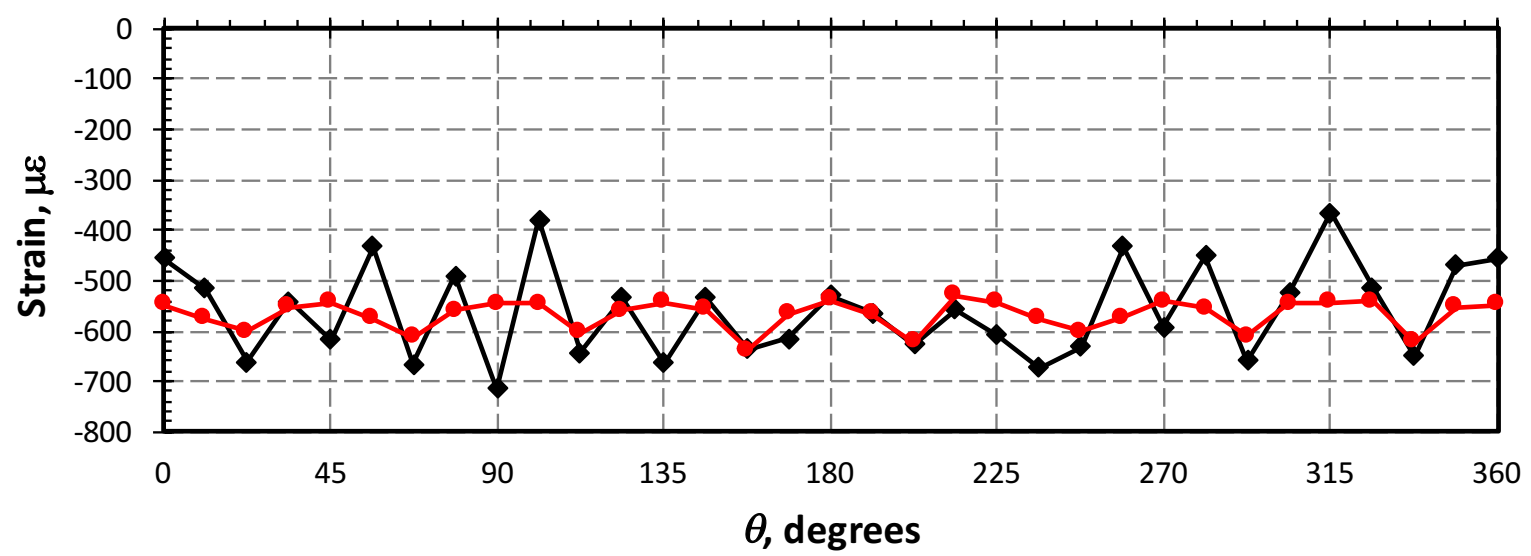

c) Bottom, near to LH2 simulator

Figure 17. ETTA1 baseline analysis comparison of membrane strain, $1.0 \mathrm{psi}$ and $59 \% \boldsymbol{P}_{c l}$. 


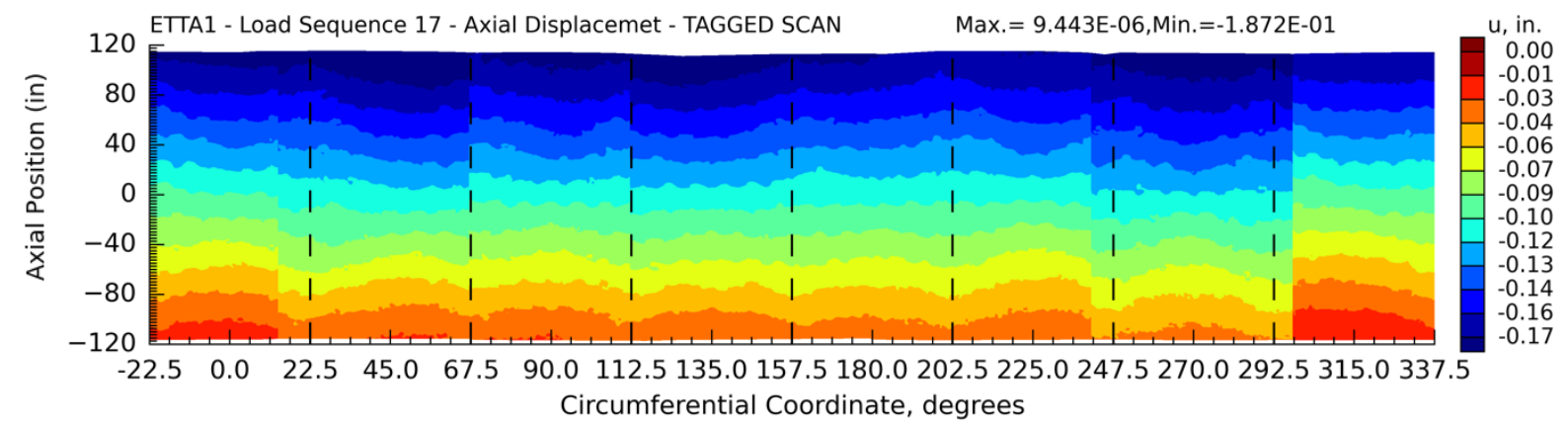

a) DIC

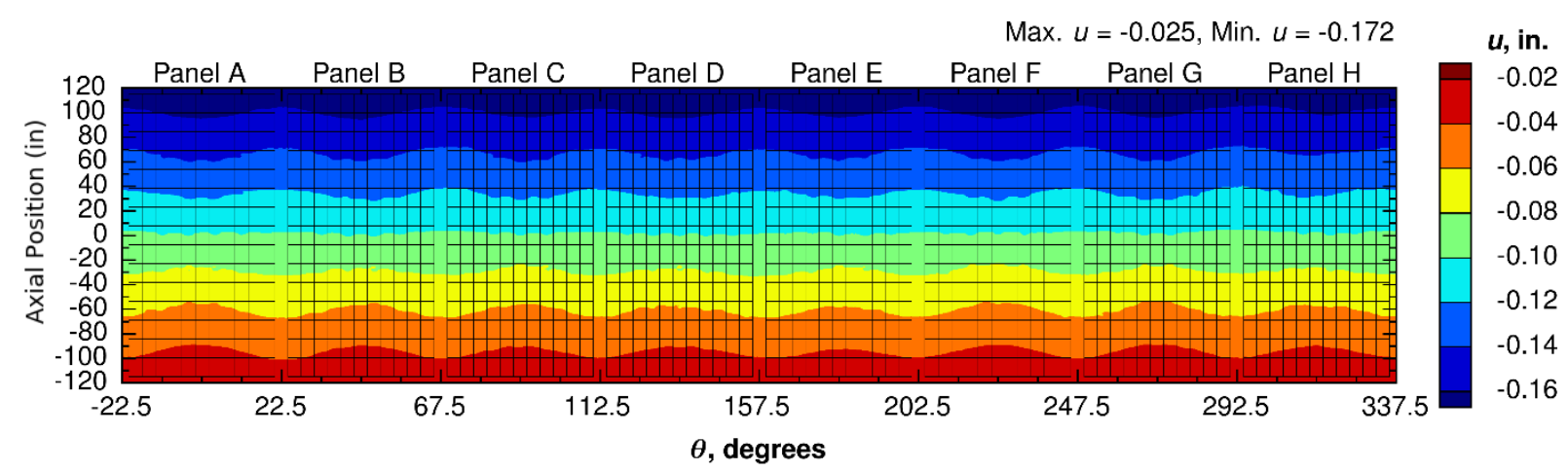

b) Baseline Analysis

Figure 18. ETTA1 baseline axial displacement contour comparison, 1.0 psi and $59 \% \boldsymbol{P}_{c l}$, LS17.

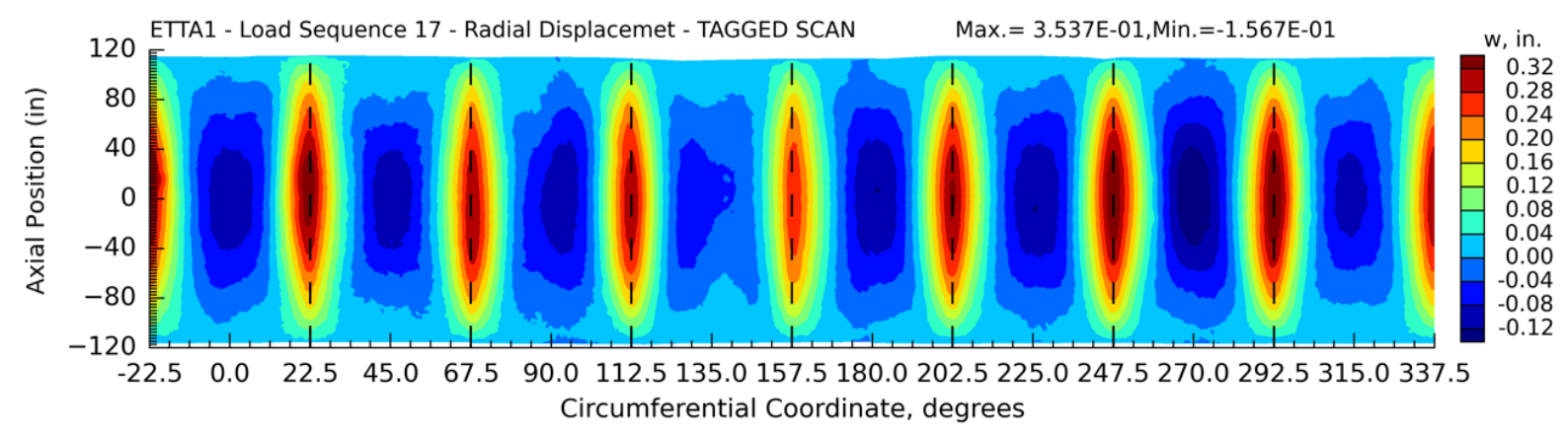

a) DIC

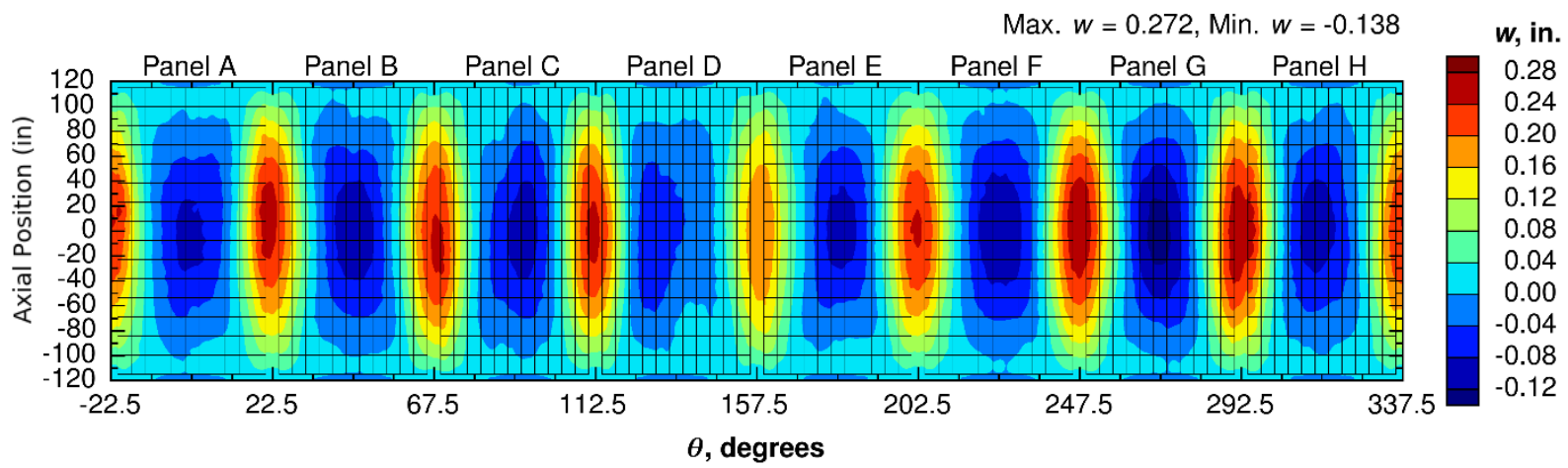

b) Baseline Analysis

Figure 19. ETTA1 baseline radial displacement contour comparison, 1.0 psi and $15 \% P_{c l}$, LS17.

American Institute of Aeronautics and Astronautics 


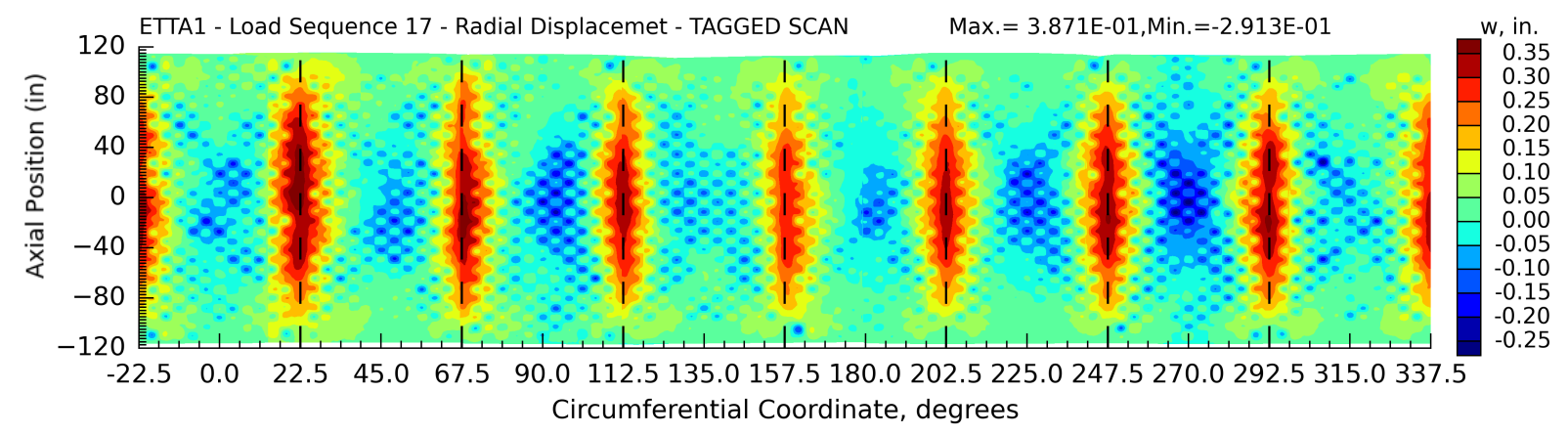

a) DIC

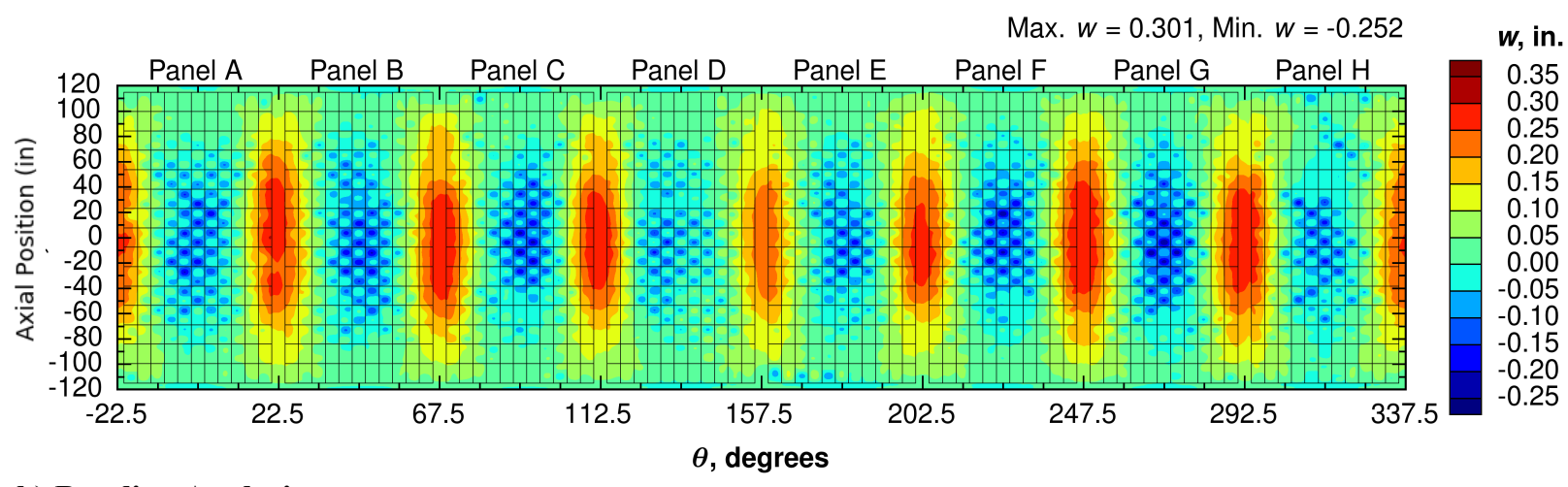

b) Baseline Analysis

Figure 20. ETTA1 baseline radial displacement contour comparison, 1.0 psi and 59\% $\boldsymbol{P}_{c l}$, LS17.

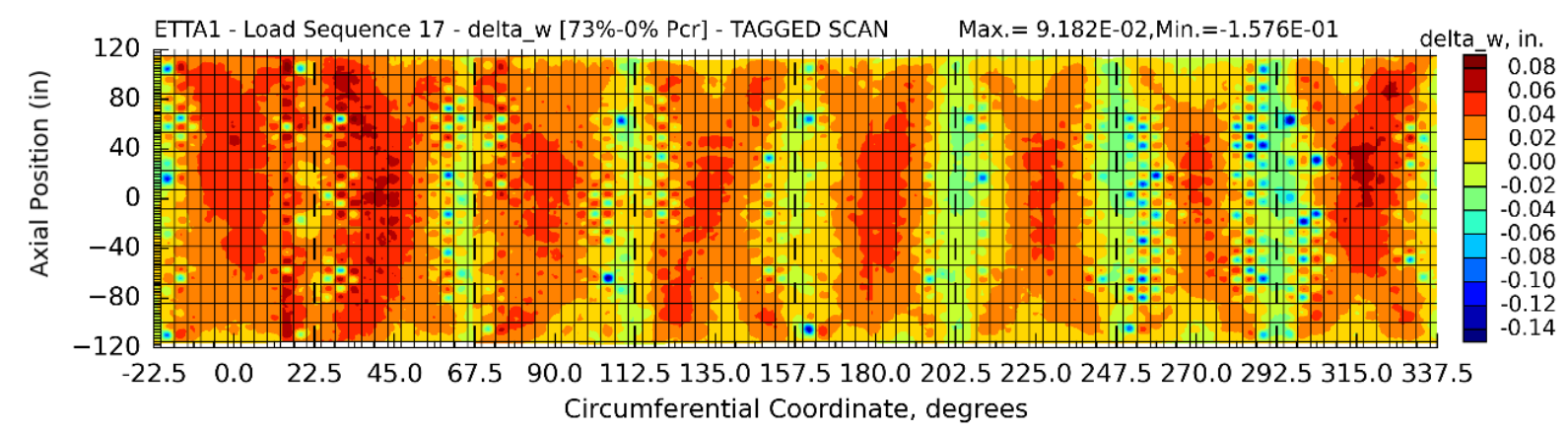

a) DIC

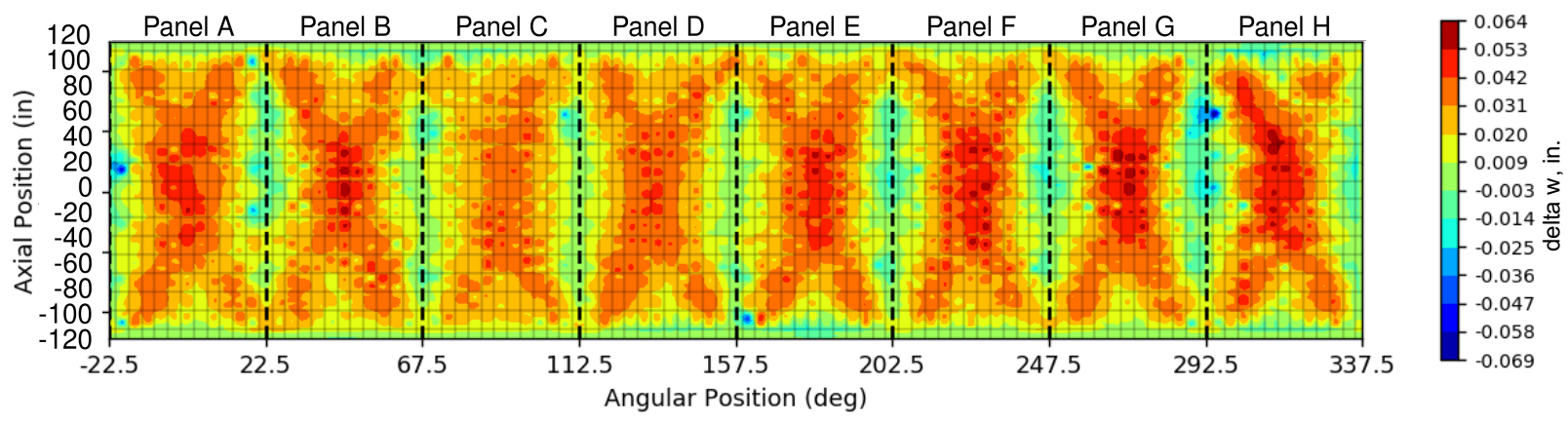

b) Baseline Analysis

Figure 21. ETTA1 baseline delta radial displacement contour comparison, 1.0 psi and $45 \% P_{c l}$ minus 1 psi, LS17. 


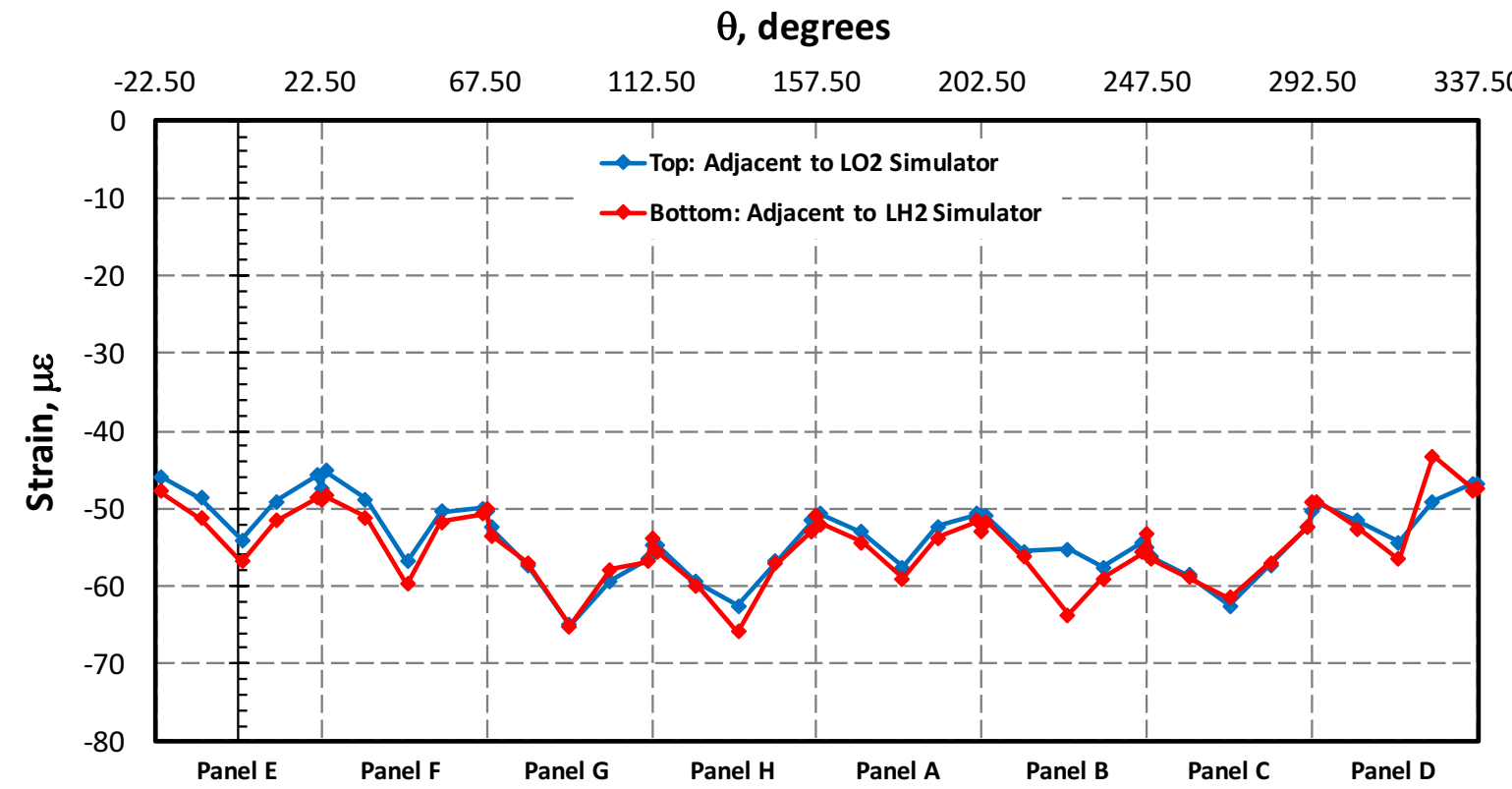

Figure 22. ETTA2, predicted strains subjected LO2 simulator and LO2 ring weight, used for shimming strain matching during installation.

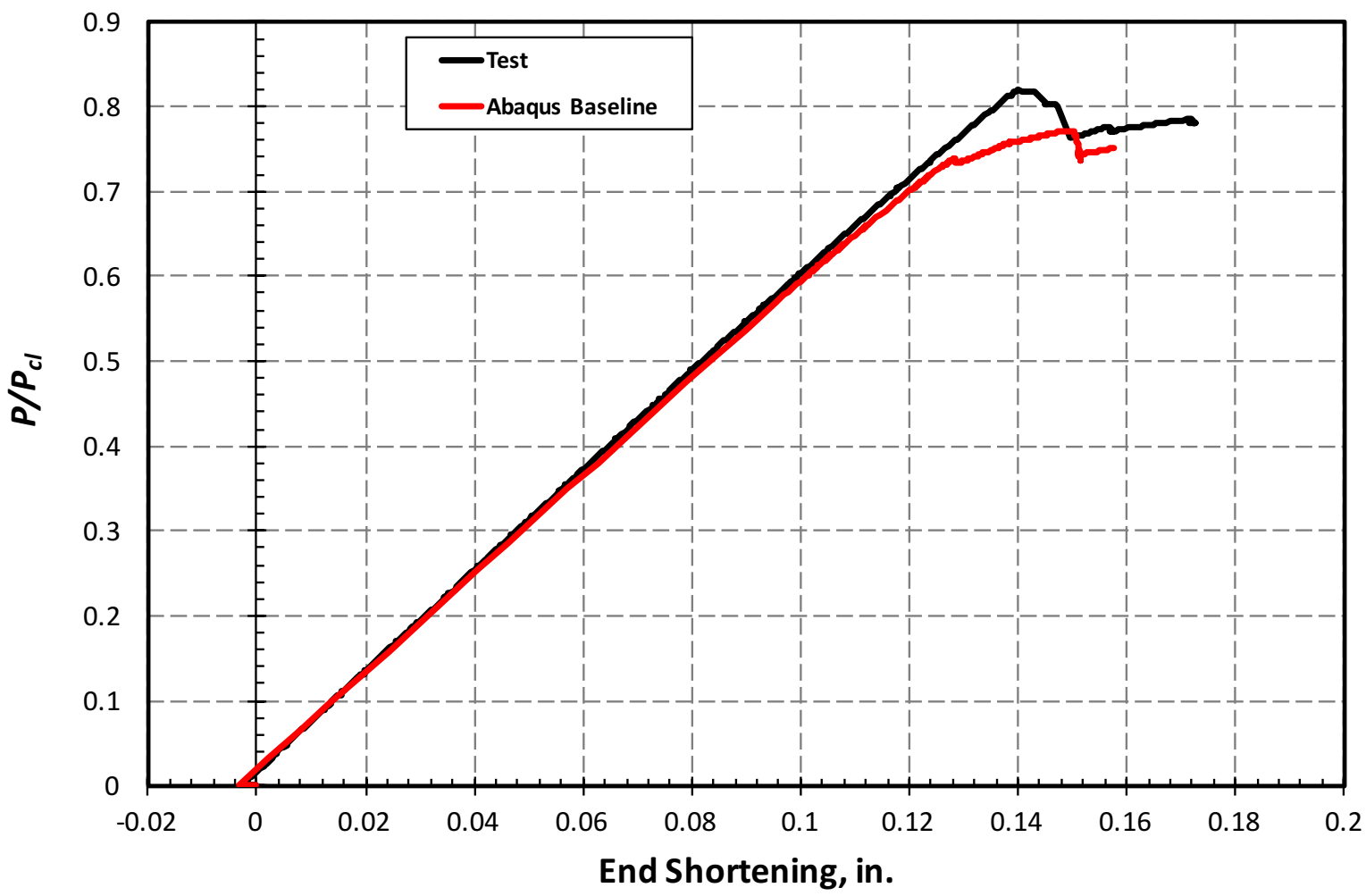

Figure 23. ETTA2 baseline analysis load factor vs. end-shortening comparison, failure sequence (LS18). 


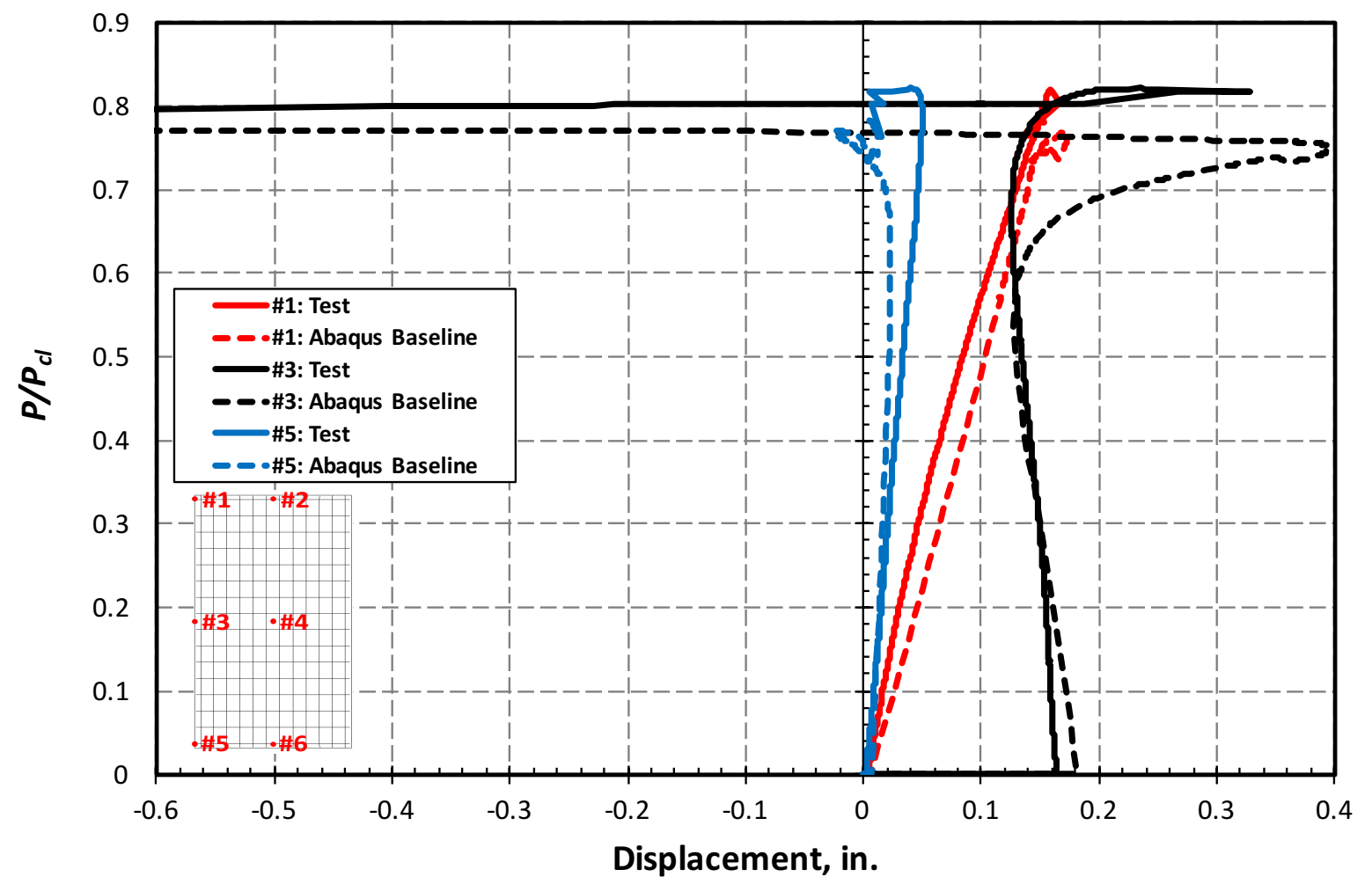

Figure 24. ETTA2 baseline E/F weld land displacement comparison, LS18.

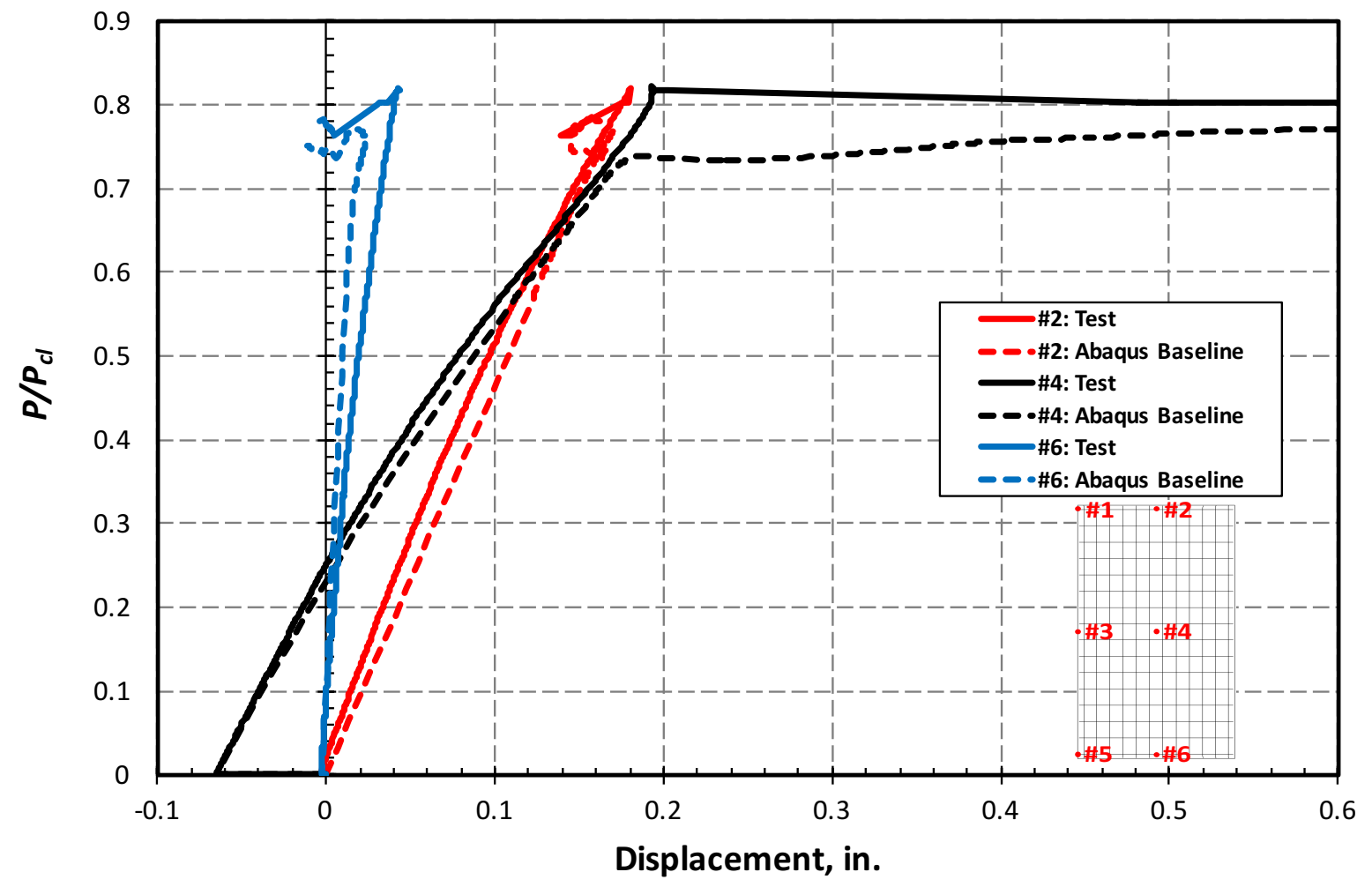

Figure 25. ETTA2 baseline panel E center displacement comparison, LS18. 


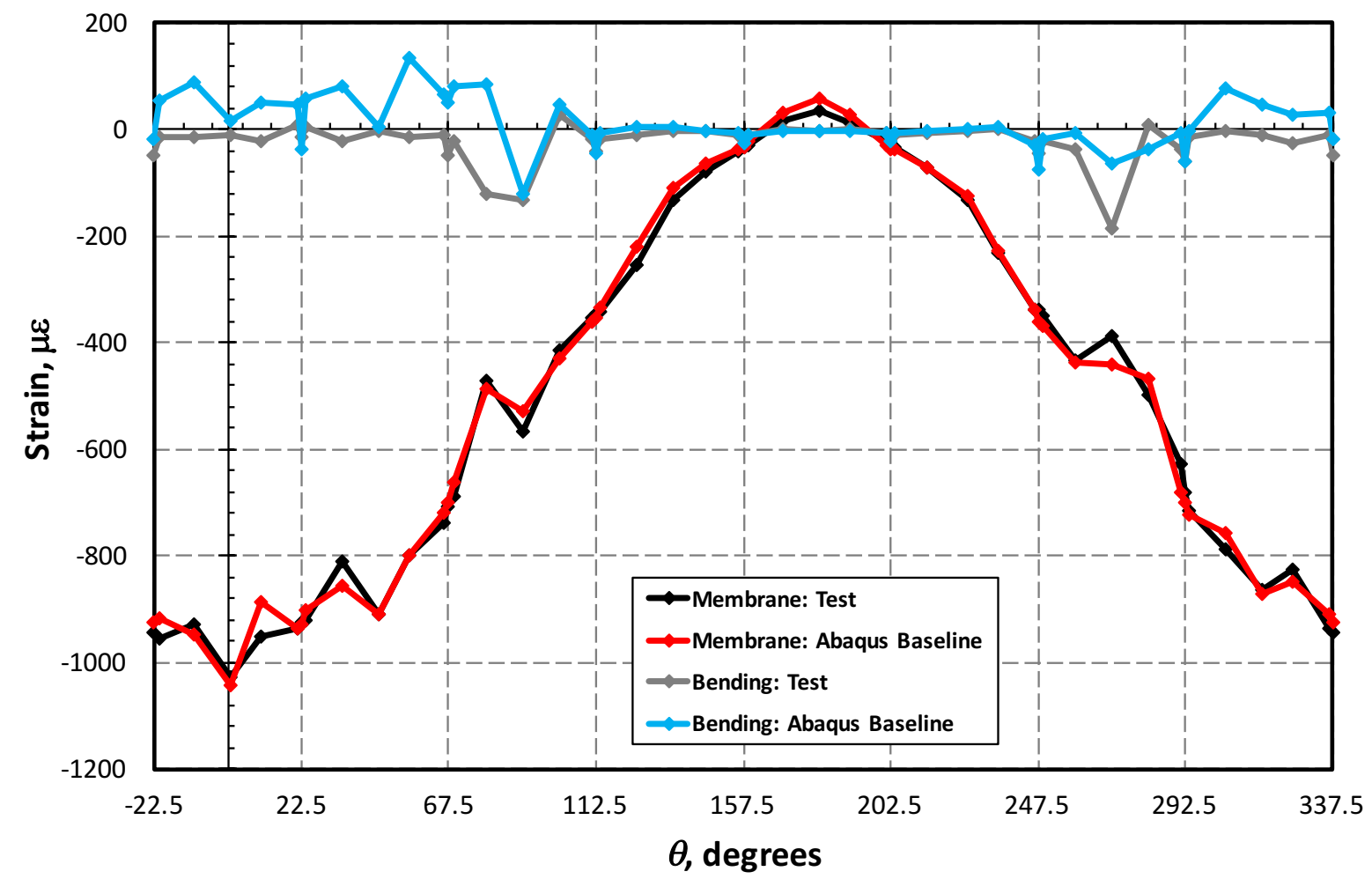

Figure 26. ETTA2 baseline membrane and bending strain comparison near the test article top, adjacent to the LO2 simulator interface, 0.5 psi plus $69.3 \% P_{c l}$, LS18.

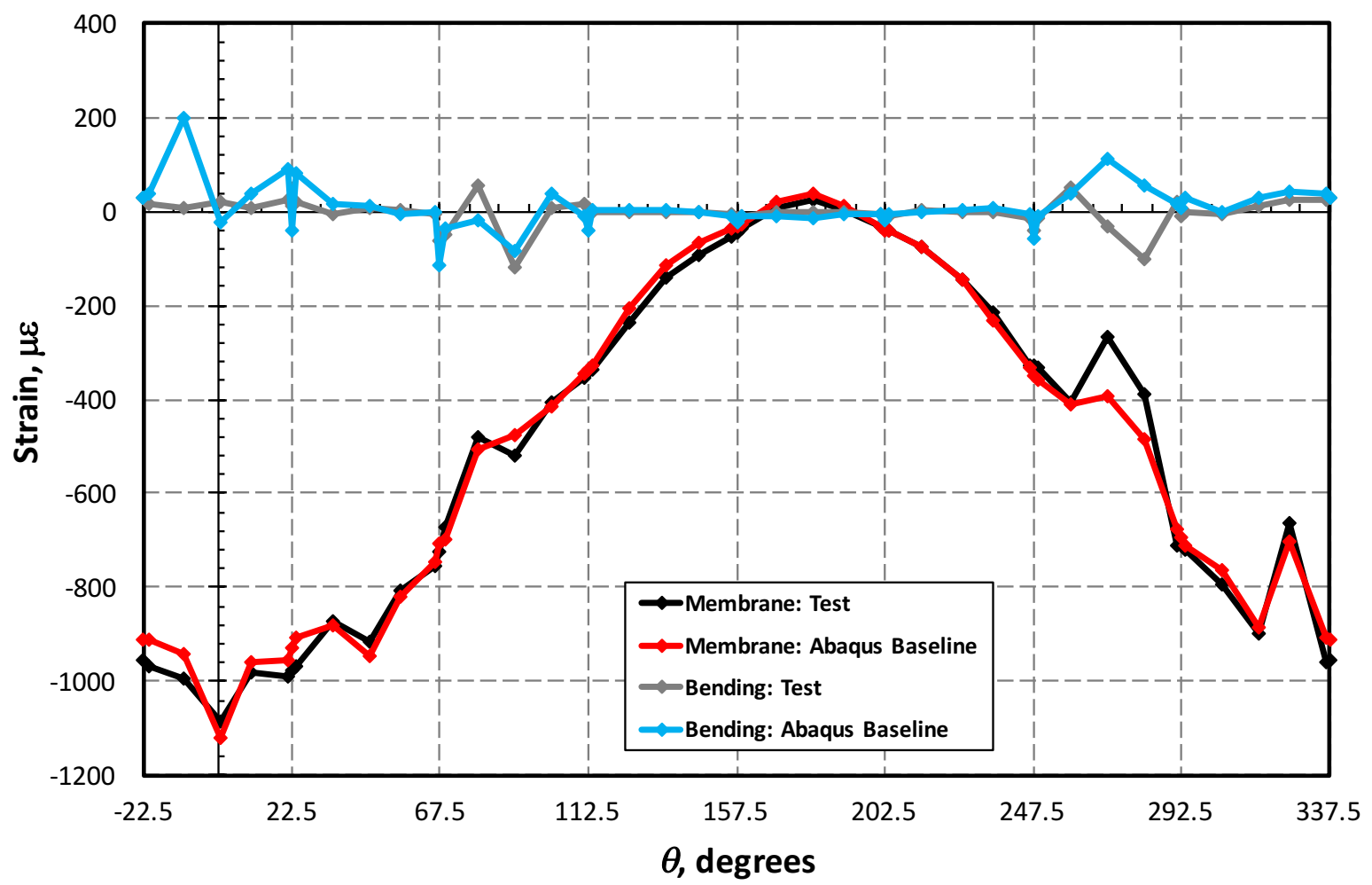

Figure 27. ETTA2 baseline membrane and bending strain comparison near the test article bottom, adjacent to the LH2 simulator interface, 0.5 psi and $69.3 \% P_{c l}$, LS18. 


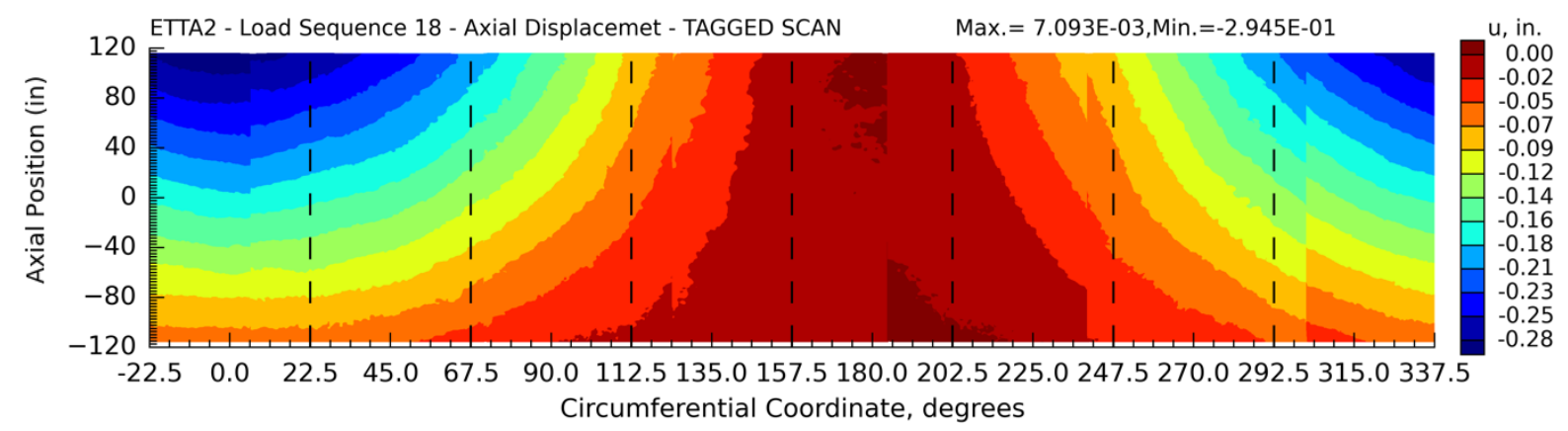

a) DIC

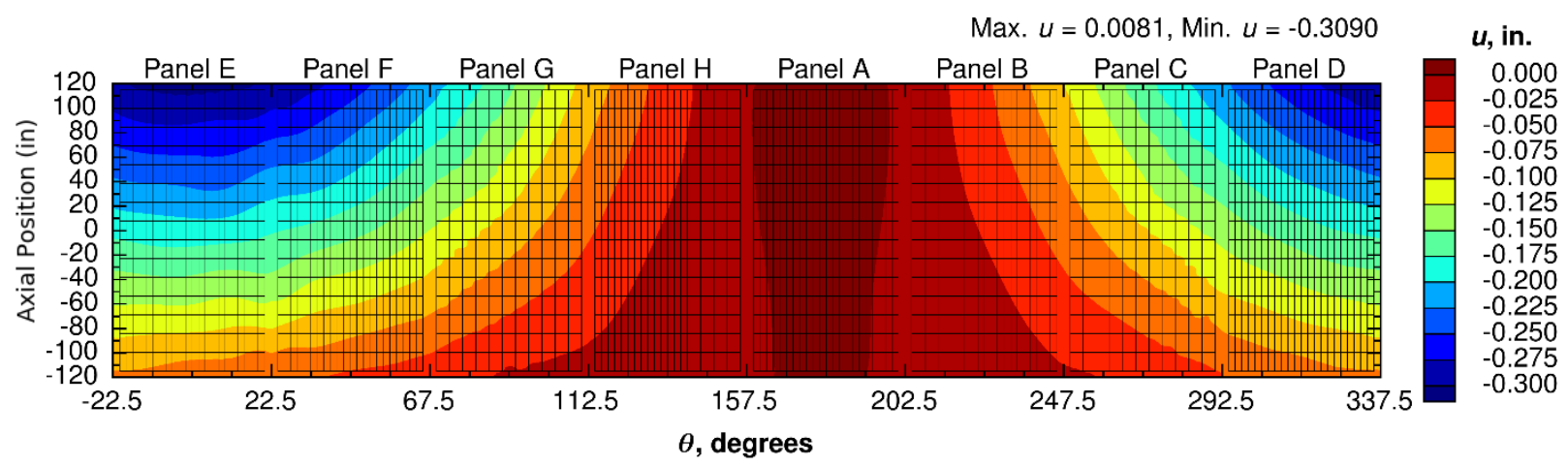

b) Analysis

Figure 28. ETTA2 baseline axial deformation (in.) comparison, 0.5 psi and $69.3 \% P_{c l}$, LS18.

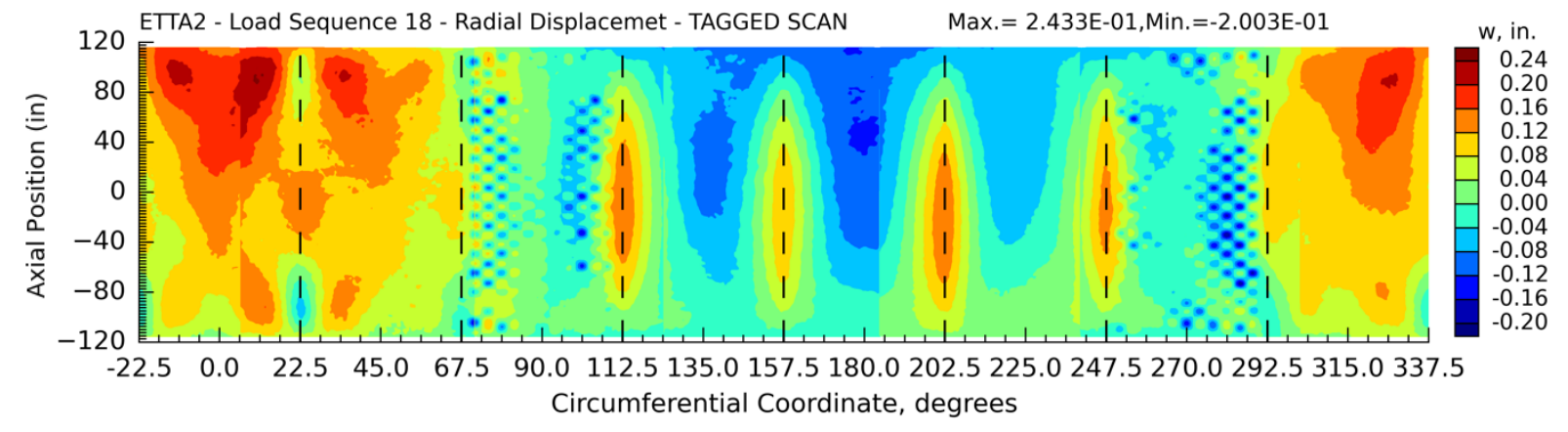

a) DIC

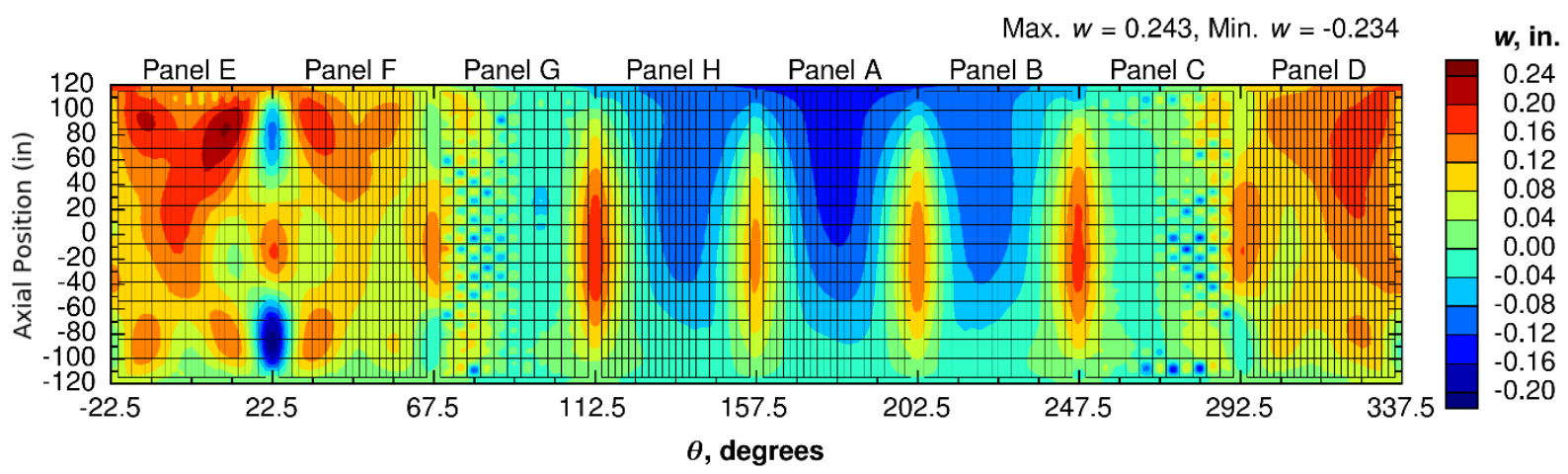

b) Analysis

Figure 29. ETTA2 baseline radial deformation (in.) comparison, 0.5 psi and $63.0 \% P_{c l}$, LS18.

American Institute of Aeronautics and Astronautics 


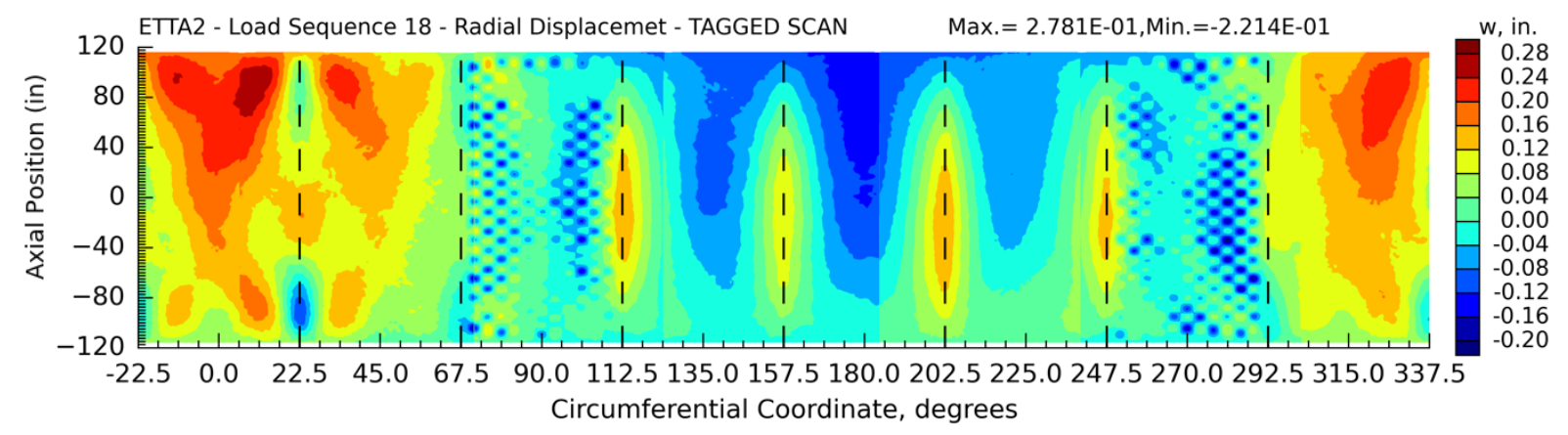

a) DIC

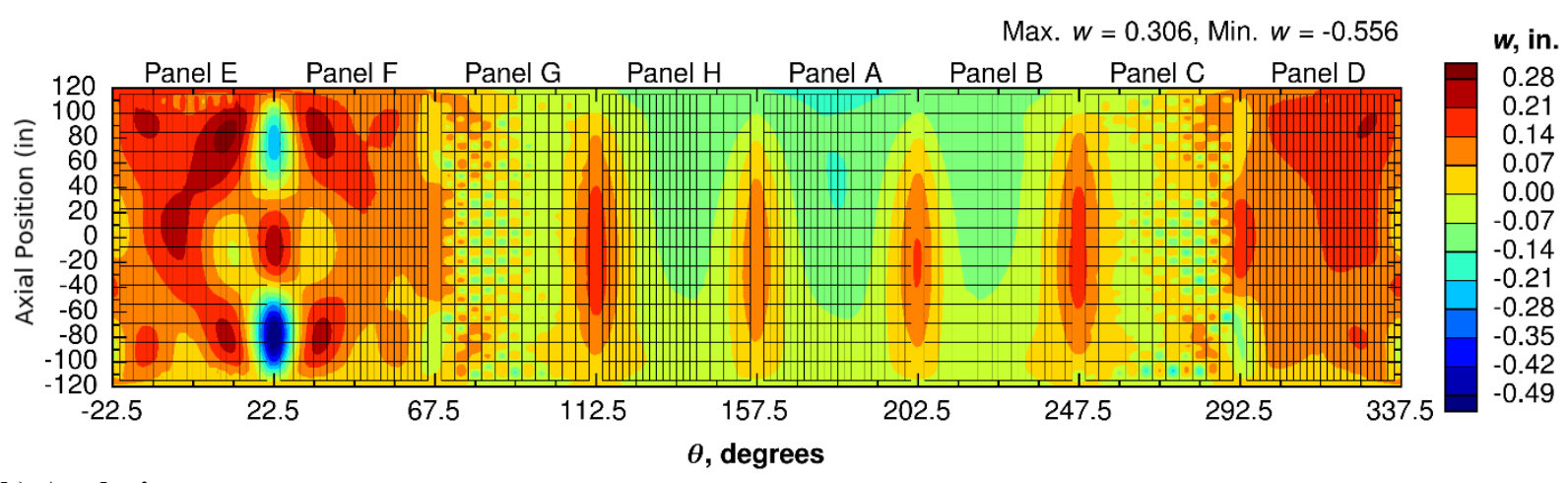

b) Analysis

Figure 30. ETTA2 baseline radial deformation (in.) comparison, 0.5 psi and $69.3 \% P_{c l}$, LS18, prior to weld land buckling predicted by analysis.
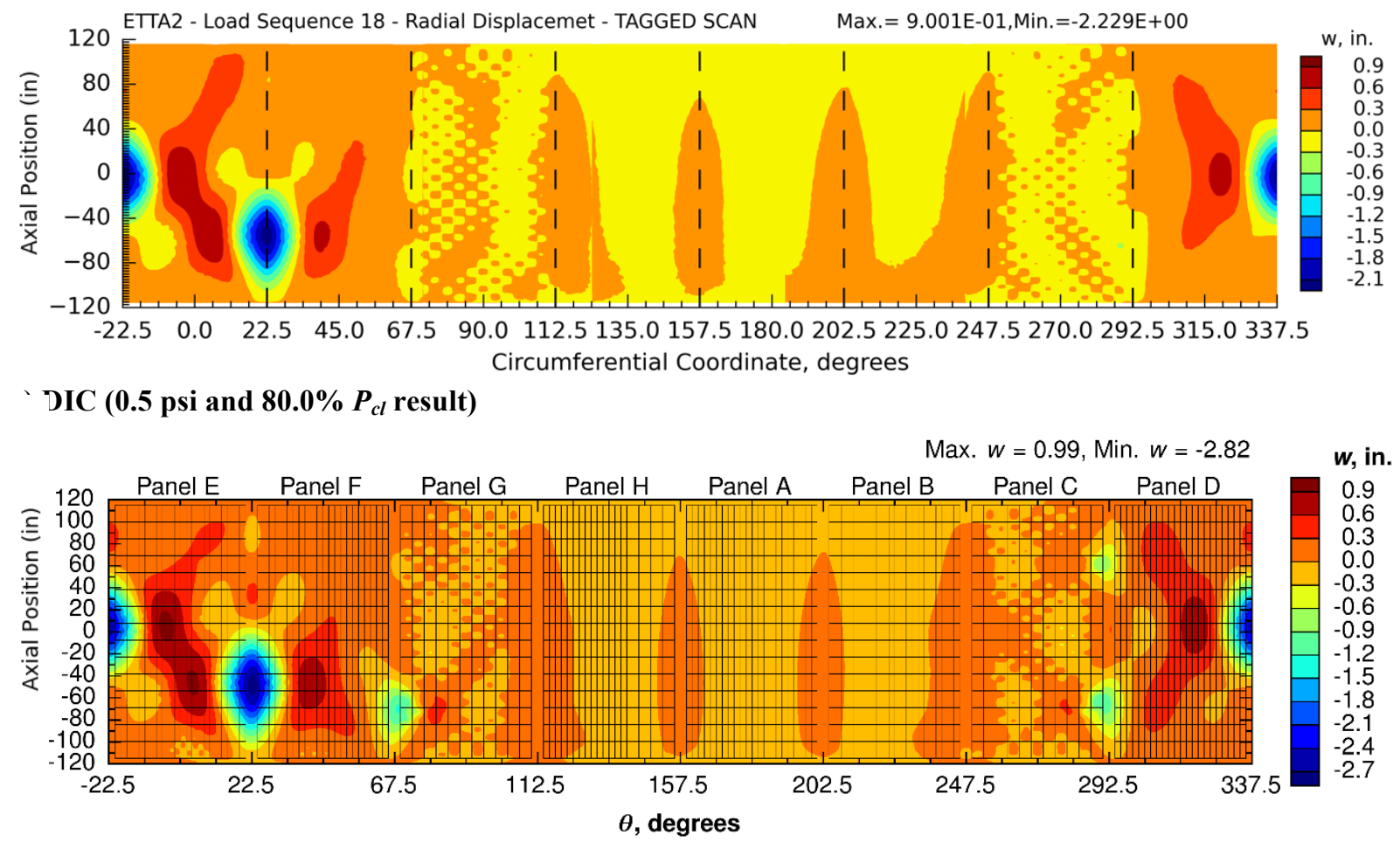

b) Analysis (0.5 psi and $77.5 \% P_{c l}$ result)

Figure 31. ETTA2 baseline maximum load pre-global-buckling radial deformation (in.) comparison, LS18. 30

American Institute of Aeronautics and Astronautics 


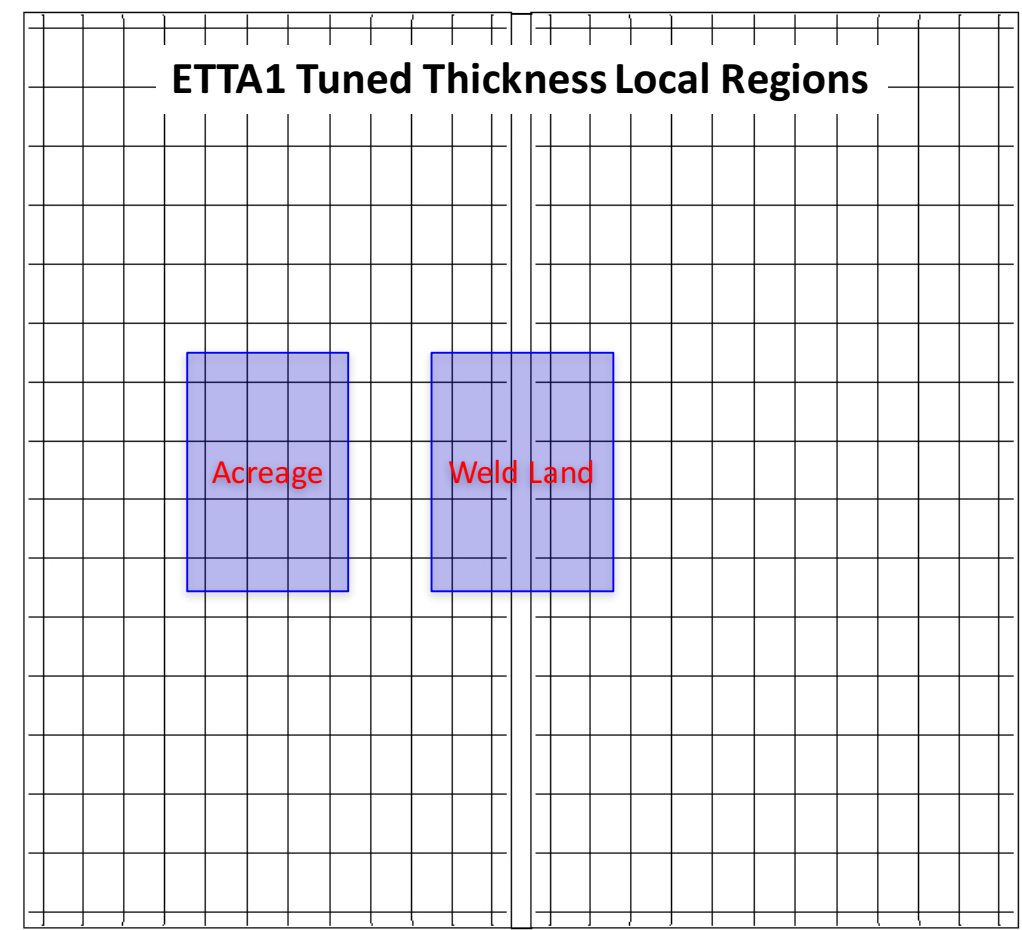

Figure 32. ETTA1 panel solid model sub-region locations with respect to panels.

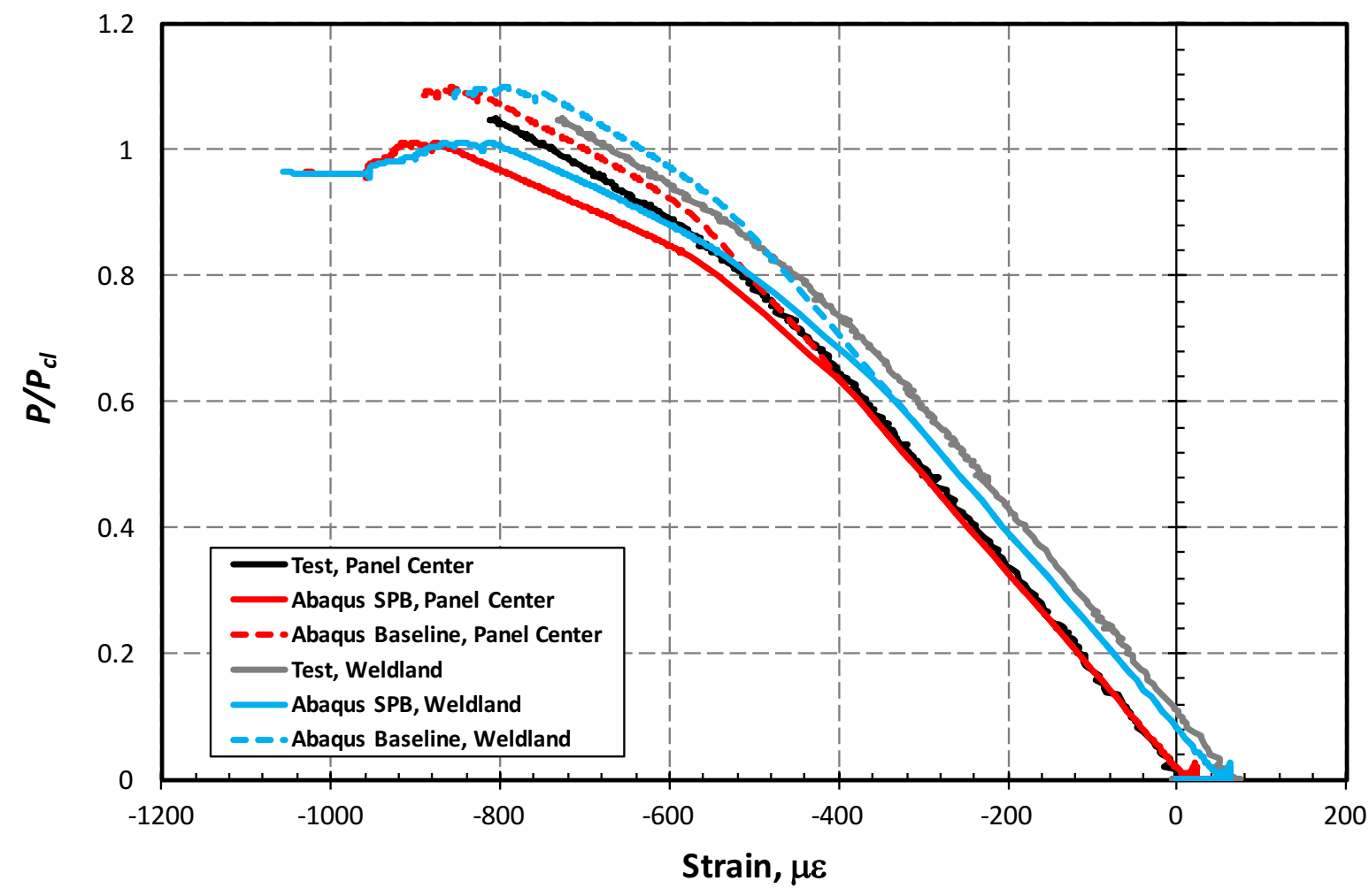

Figure 33. ETTA1 average strain using DIC " $L$ " markers, final failure sequence, SPB and baseline. 


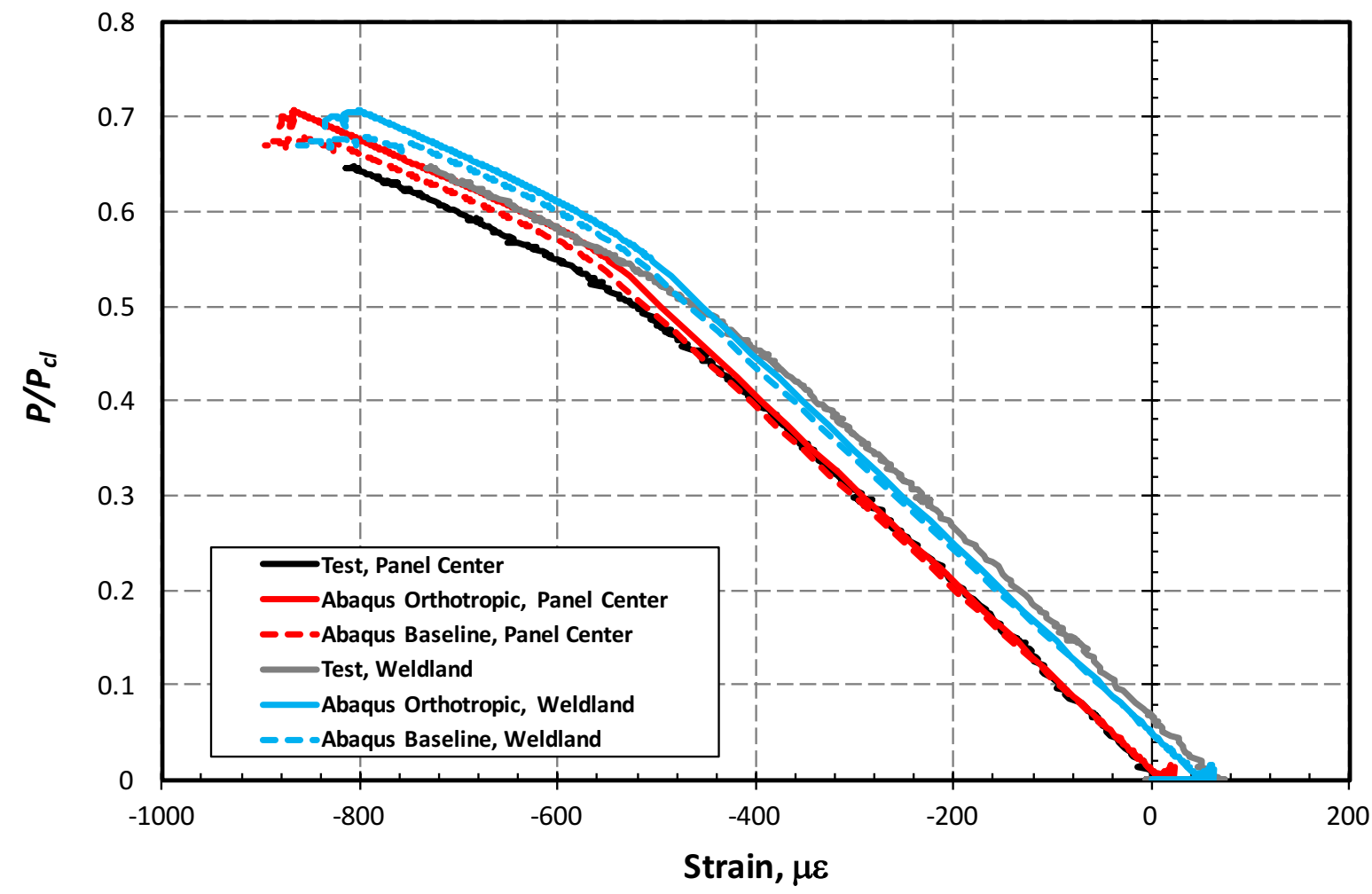

Figure 34. ETTA1 average strain using DIC "L" markers, final failure sequence, orthotropic and baseline.

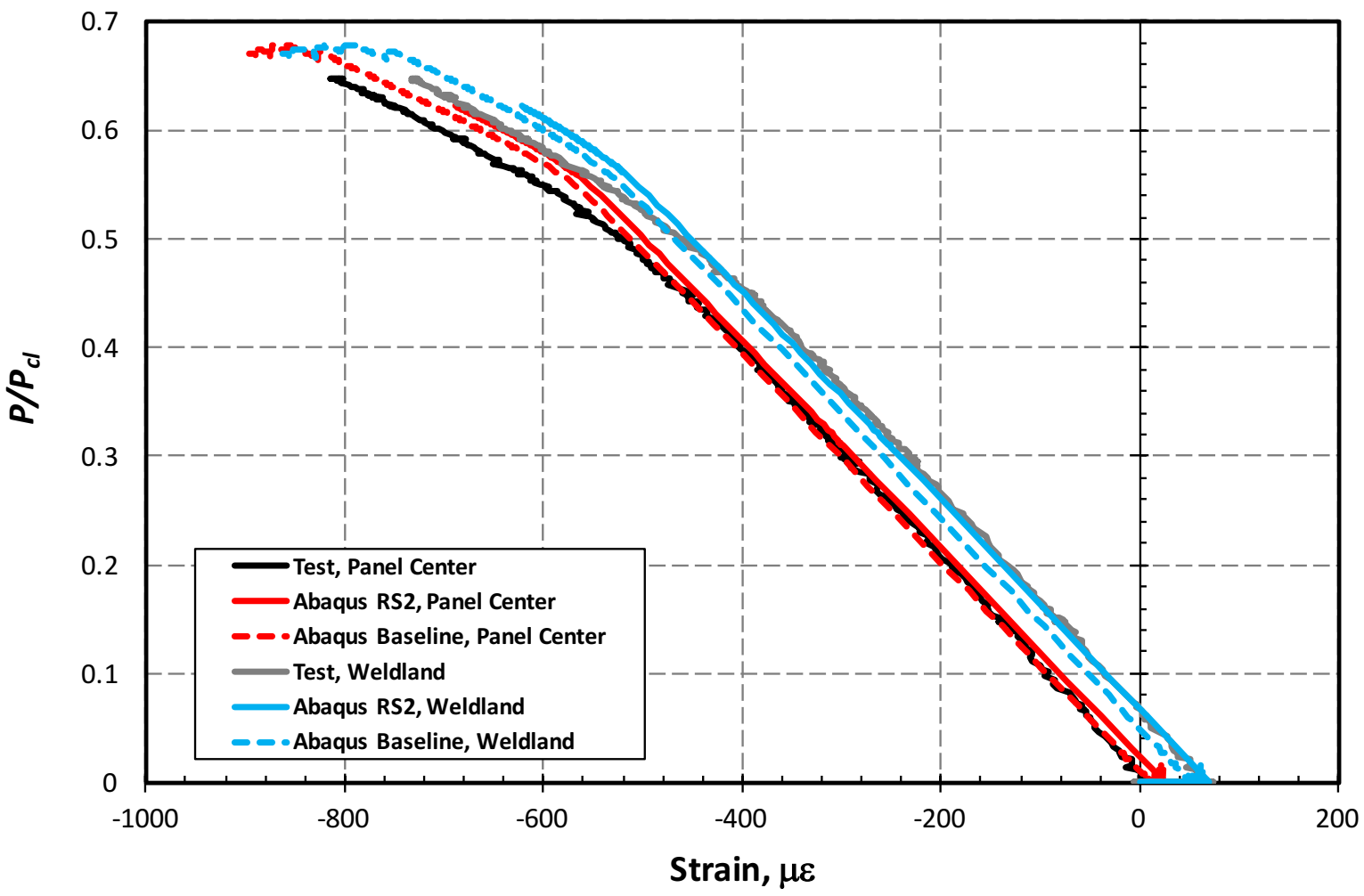

Figure 35. ETTA1 average strain using DIC " $L$ " markers, final failure sequence, RS2 and baseline. 


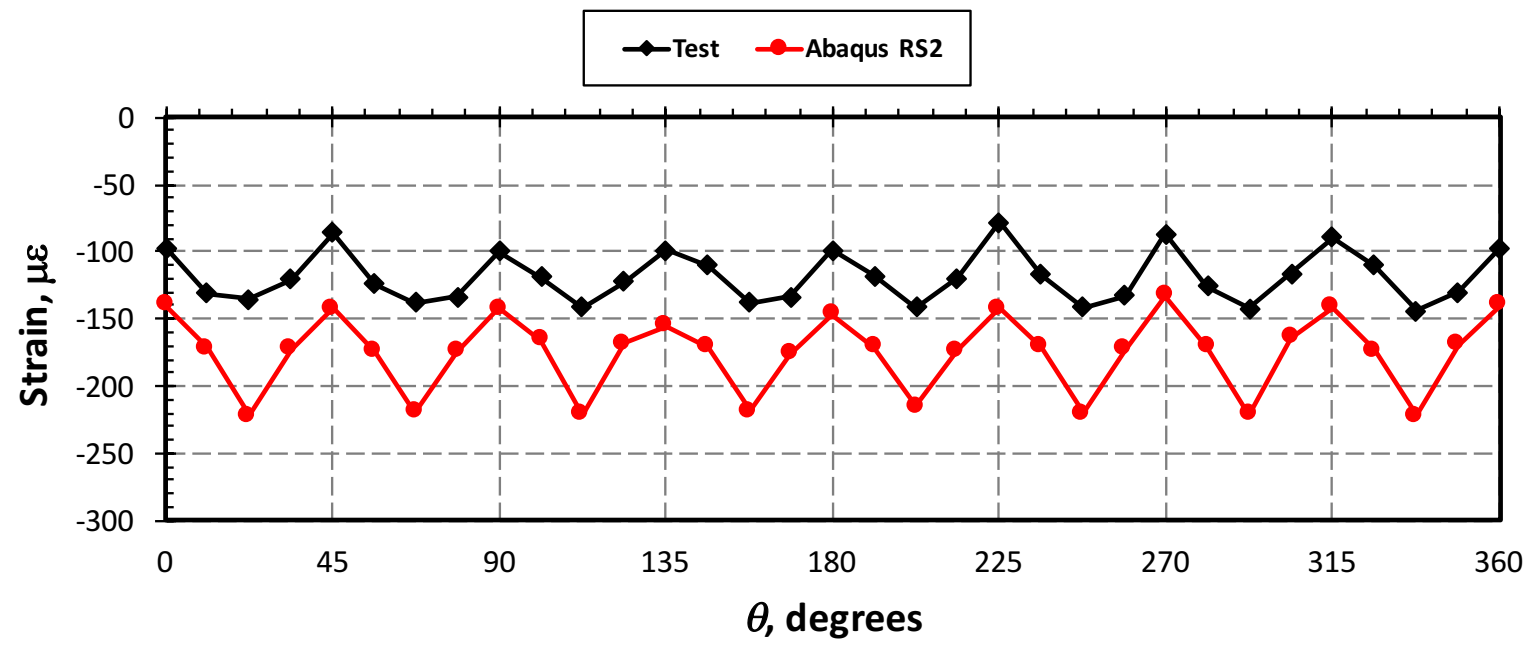

a) Top, near to LO2 simulator

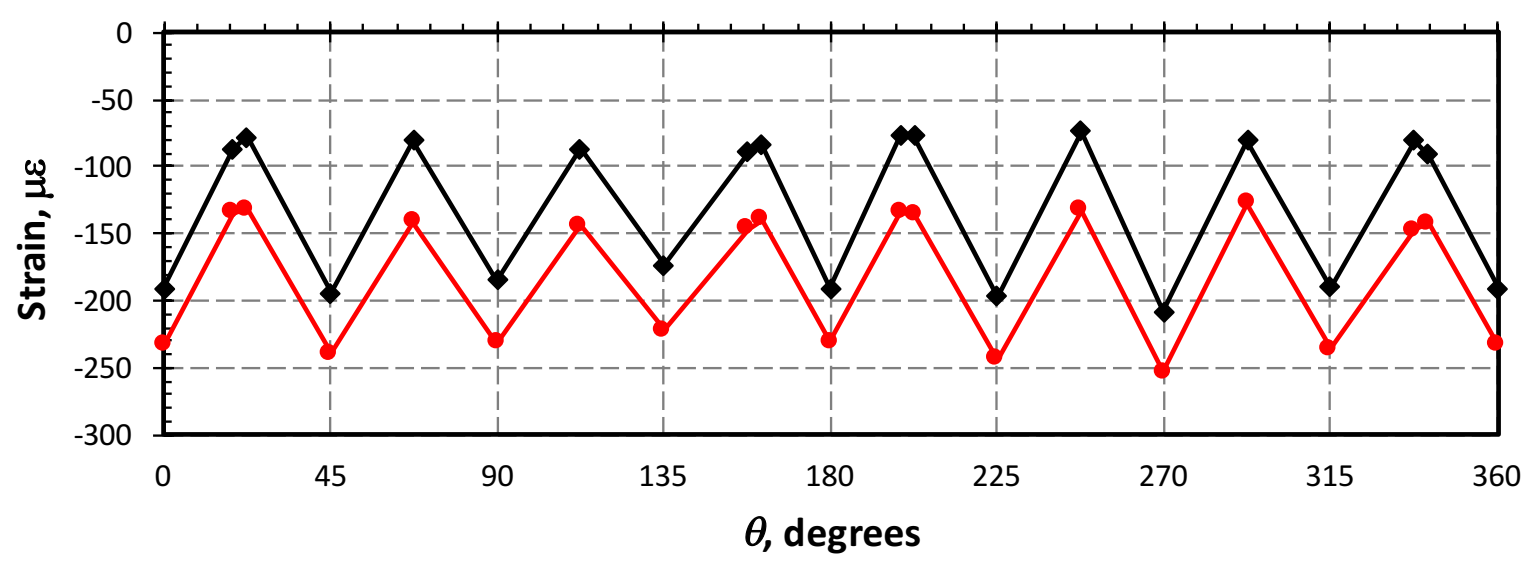

b) Mid-length

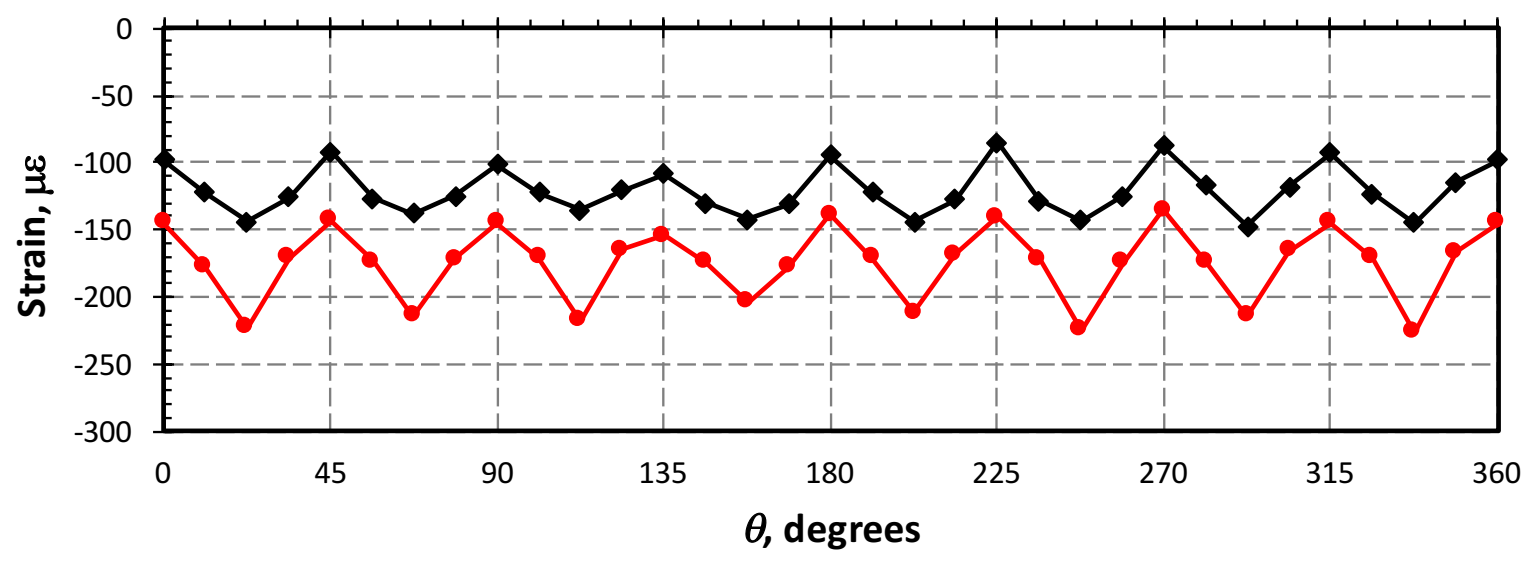

c) Bottom, near to $\mathrm{LH} 2$ simulator

Figure 36. ETTA1 RS2 analysis comparison of membrane strain, 1.0 psi and $15 \% \boldsymbol{P}_{c l}$. 


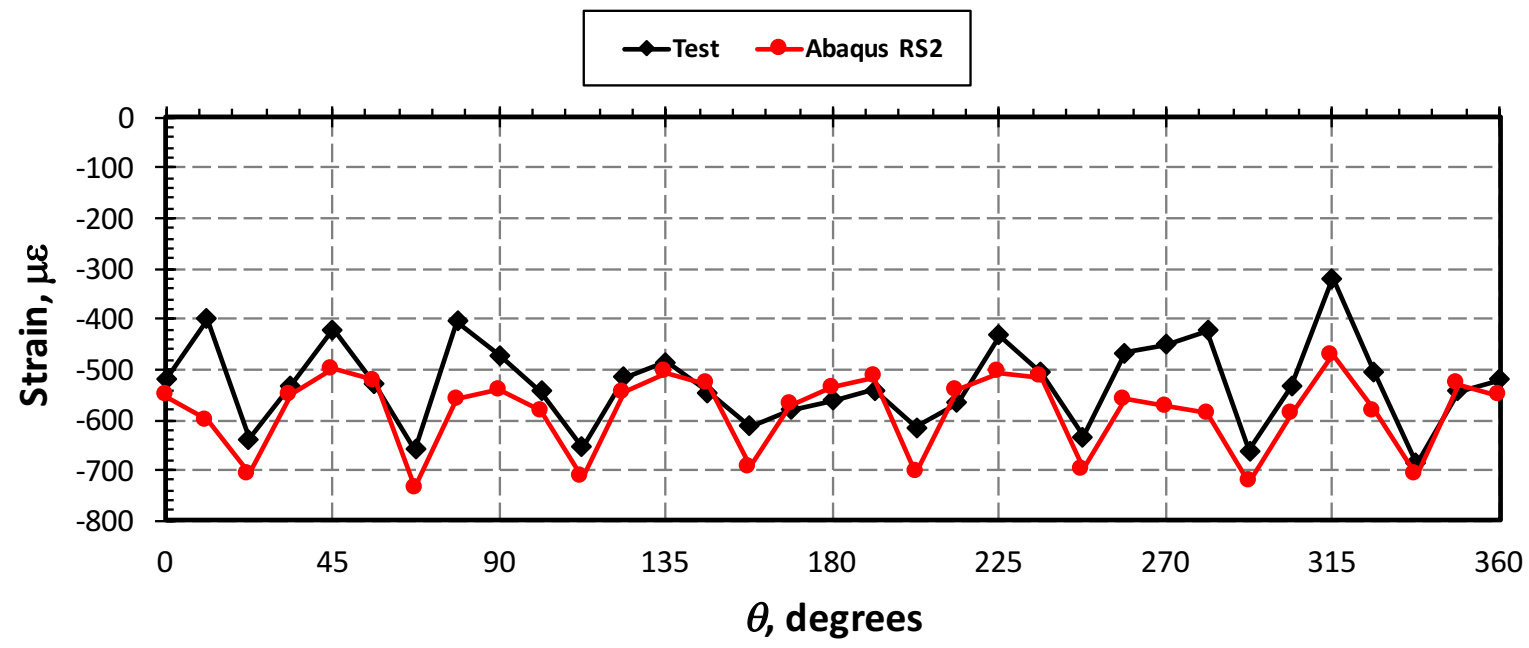

a) Top, near to $\mathrm{LO2}$ simulator

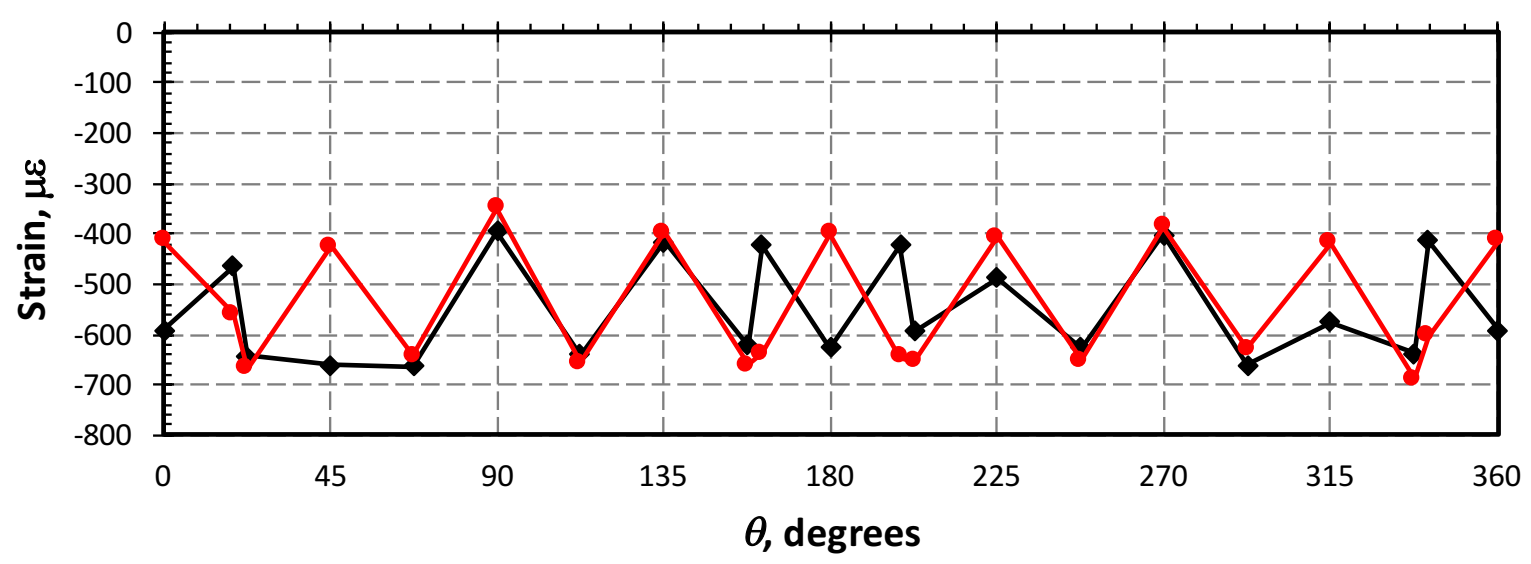

b) Mid-length

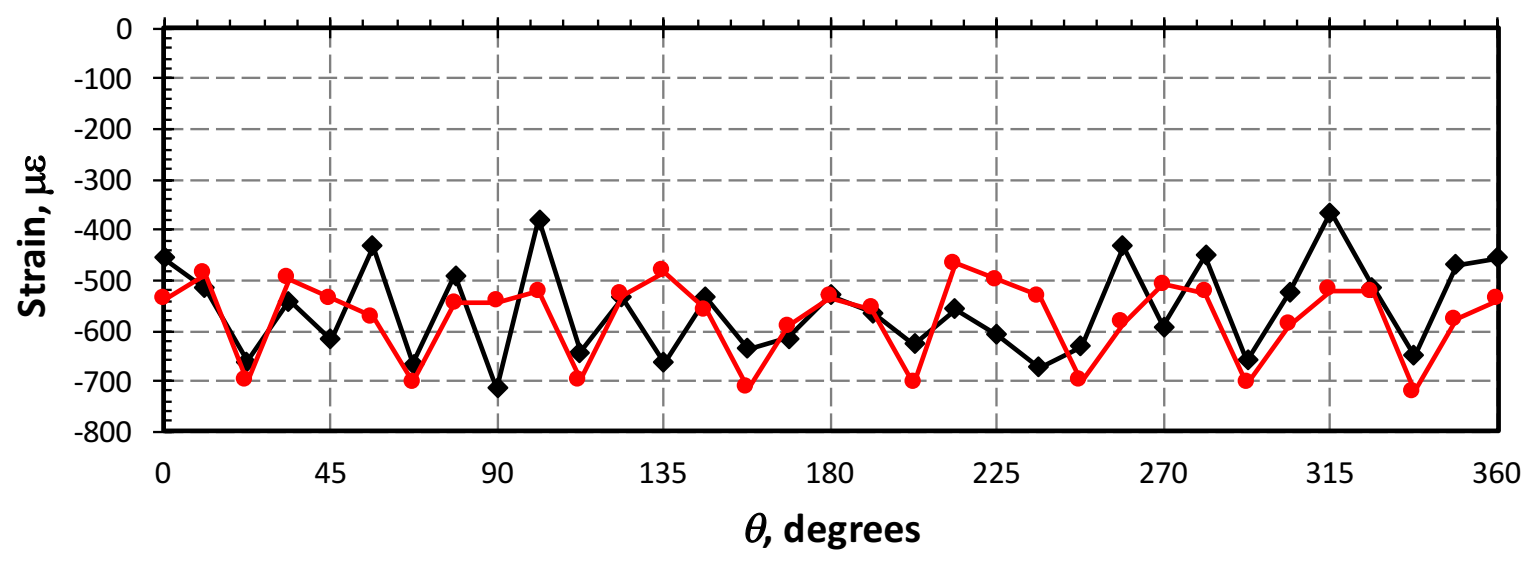

c) Bottom, near to $\mathrm{LH} 2$ simulator

Figure 37. ETTA1 RS2 analysis comparison of membrane strain, 1.0 psi and $59 \% \boldsymbol{P}_{c l}$. 